\title{
Identification of Natural Molecular Determinants of Ross River Virus Type I Interferon Modulation
}

\author{
Xiang Liu, a,b Margit Mutso, ${ }^{\mathrm{a}, \mathrm{b}}$ Liubov Cherkashchenko, ${ }^{\mathrm{c}}$ Eva Zusinaite, ${ }^{c}$ (D) Lara J. Herrero, ${ }^{a}$ Stephen L. Doggett, ${ }^{\mathrm{d}}$ \\ John Haniotis, ${ }^{\text {d }}$ (D) Andres Merits, c Belinda L. Herring, ${ }^{a}$ Adam Taylor, a,b (D) Suresh Mahalingam ${ }^{\mathrm{a}, \mathrm{b}}$ \\ alnstitute for Glycomics, Griffith University, Southport, Queensland, Australia \\ bMenzies Health Institute Queensland, Griffith University, Southport, Queensland, Australia \\ Institute of Technology, University of Tartu, Tartu, Estonia \\ dDepartment of Medical Entomology, Pathology West, ICPMR, Westmead Hospital, Westmead, NSW, Australia \\ Adam Taylor and Suresh Mahalingam are joint last authors.
}

ABSTRACT Ross River virus (RRV) belongs to the genus Alphavirus and is prevalent in Australia. RRV infection can cause arthritic symptoms in patients and may include rash, fever, arthralgia, and myalgia. Type I interferons (IFN) are the primary antiviral cytokines and trigger activation of the host innate immune system to suppress the replication of invading viruses. Alphaviruses are able to subvert the type I IFN system, but the mechanisms used are ill defined. In this study, seven RRV field strains were analyzed for induction of and sensitivity to type I IFN. The sensitivities of these strains to human IFN- $\beta$ varied significantly and were highest for the RRV 2548 strain. Compared to prototype laboratory strain RRV-T48, RRV 2548 also induced higher type I IFN levels both in vitro and in vivo and caused milder disease. To identify the determinants involved in type I IFN modulation, the region encoding the nonstructural proteins (nsPs) of RRV 2548 was sequenced, and 42 amino acid differences from RRV-T48 were identified. Using fragment swapping and site-directed mutagenesis, we discovered that substitutions E402A and $\mathrm{R} 522 \mathrm{Q}$ in nsP1 as well as Q619R in nsP2 were responsible for increased sensitivity of RRV 2548 to type I IFN. In contrast, substitutions A31T, N219T, S580L, and Q619R in nsP2 led to induction of higher levels of type I IFN. With exception of E402A, all these variations are common for naturally occurring RRV strains. However, they are different from all known determinants of type I IFN modulation reported previously in nsPs of alphaviruses.

IMPORTANCE By identifying natural Ross River virus (RRV) amino acid determinants for type I interferon (IFN) modulation, this study gives further insight into the mechanism of type I IFN modulation by alphaviruses. Here, the crucial role of type I IFN in the early stages of RRV disease pathogenesis is further demonstrated. This study also provides a comparison of the roles of different parts of the RRV nonstructural region in type I IFN modulation, highlighting the importance of nonstructural protein 1 (nsP1) and nsP2 in this process. Three substitutions in nsP1 and nsP2 were found to be independently associated with enhanced type I IFN sensitivity, and four independent substitutions in nsP2 were important in elevated type I IFN induction. Such evidence has clear implications for RRV immunobiology, persistence, and pathology. The identification of viral proteins that modulate type I IFN may also have importance for the pathogenesis of other alphaviruses.

KEYWORDS Ross River virus, alphavirus, interferons, viral determinants

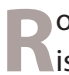
oss River virus (RRV) is a member of the Alphavirus genus (family Togaviridae) that is prevalent throughout Australia and is a major concern in Papua New Guinea and Pacific Island countries (1). Recent evidence suggests ongoing endemic circulation of
Citation Liu X, Mutso M, Cherkashchenko L, Zusinaite E, Herrero LJ, Doggett SL, Haniotis J, Merits A, Herring BL, Taylor A, Mahalingam S. 2020. Identification of natural molecular determinants of Ross River virus type I interferon modulation. J Virol 94:e01788-19. https://doi.org/10.1128/JVI.01788-19. Editor Mark T. Heise, University of North Carolina at Chapel Hill

Copyright $\odot 2020$ American Society for Microbiology. All Rights Reserved. Address correspondence to Suresh Mahalingam, s.mahalingam@griffith.edu.au. Received 17 October 2019 Accepted 24 January 2020 Accepted manuscript posted online 29 January 2020

Published 31 March 2020 
RRV in Fiji (2). RRV is transmitted by mosquitoes. On average, approximately 5,000 clinical cases of RRV disease are reported annually in Australia (3, 4). According to Australia's National Notifiable Diseases Surveillance System (NNDSS), 9,542 RRV infection cases were reported in 2015, representing a 23-year high (5). The most common clinical manifestations of RRV disease include polyarthritis and myalgia, which can last up to 6 months. Some patients may also develop fever and rash (6). It is estimated that the annual cost of RRV disease, including testing, treatment, and lost earnings, is approximately AU\$20 million (4). Common, and often ineffective, treatments for patients with RRV disease include analgesics and nonsteroidal anti-inflammatory drugs, as there are currently no commercially available treatments or vaccines (6).

The type I interferon (IFN) system is the first line of defense against invading viral pathogens. The system is triggered upon virus infection, leading to the activation of interferon-stimulated genes (ISGs) (7-10). Many viruses, including alphaviruses, have evolved to counteract the type I IFN system (11-13). Alphavirus infection generally results in rapid shutdown of host cell transcription and protein synthesis in favor of viral protein synthesis (14). This was also thought to be the main mechanism of alphavirus type I IFN suppression. However, alphaviruses also exert more specific effects on the type I IFN system. Recent work with Sindbis virus (SINV), Venezuelan equine encephalitis virus (VEEV), and chikungunya virus (CHIKV) demonstrated that inhibition of STAT1 phosphorylation and nuclear export of STAT1 by these viruses, independent of host protein shutoff, limited type I IFN signaling (15-18). For CHIKV, SINV, and Semliki Forest virus (SFV), which together with RRV belong to the Old World alphaviruses, IFN modulation is mediated by the viral nonstructural (replicase) proteins (nsPs) $(12-15,19$, 20). Despite this, our knowledge of how alphaviruses suppress IFN independent of host shutoff is limited and often contradictory $(12,20,21)$. In addition, the precise molecular determinants of type I IFN modulation/antagonism are still not clear.

The field strains of RRV used in this study have been isolated from different species of Australian mosquitoes found in different states of Australia (Fig. 1). These field strains provide us with a valuable natural pool of RRV with variation in biological activity and, correspondingly, viral gene sequences. We hypothesize that gene variations naturally occurring in these RRV field isolates modulate the type I IFN response to infection. Several studies have investigated the response to type I IFN induction during alphavirus infection $(14,22,23)$. In contrast, type I IFN sensitivity is one of the least understood aspects of alphavirus infection. In this study, the RRV field strains were found to exhibit differences in type I IFN sensitivity, providing an opportunity to identify naturally occurring determinants of this phenotype. RRV field strain RRV 2548, which was isolated in 1989 in New South Wales $(24,25)$, exhibits greater ability to induce type I IFN both in vitro and in vivo than the prototype RRV-T48 strain. We examined the pathogenesis of RRV 2548 in vivo and assessed how different pathogenic phenotypes related to differences in virus genotype and IFN induction/sensitivity. Our data indicate that nsP1 A402 and Q522 as well as nsP2 R619 residues are associated with RRV type I IFN sensitivity, while nsP2 residues T31, T219, L580, and R619 are required for enhanced type I IFN induction.

\section{RESULTS}

RRV field strains differ in sensitivity to human IFN- $\beta$. To screen the type I IFN sensitivity of RRV field strains, Vero cells which are unable to produce type I IFN but can react to exogenous IFN were mock treated with phosphate-buffered saline (PBS) or treated with $0.05 \mathrm{ng} / \mathrm{ml}$ human IFN- $\beta$ and infected at a multiplicity of infection (MOI) of 0.1 with different RRV strains. Cell culture media were collected for plaque assay $24 \mathrm{~h}$ postinfection (p.i.). The replication of all RRV field strains was inhibited by IFN- $\beta$ treatment. For the strains RRV 4767, RRV 28937, and RRV 36750 as well as for laboratory stain RRV-T48, inhibition was modest, approximately 8.5-, 22.5-, 9-, and 5.2-fold, respectively. In contrast, for RRV 2548, RRV 53302, RRV 145290, and RRV 14291, more prominent $>100$-fold inhibition of replication was observed (Fig. 2). Among all RRV field strains, RRV 2548 showed the greatest sensitivity to human IFN- $\beta$, with approximately 


\begin{tabular}{|c|c|c|c|c|}
\hline $\begin{array}{l}\text { Isolate } \\
\text { Number }\end{array}$ & $\begin{array}{c}\text { Year } \\
\text { isolated }\end{array}$ & $\begin{array}{l}\text { Mosquito } \\
\text { Species }\end{array}$ & Trap Location & Passage History \\
\hline 2548 & 1989 & Cx annul & Griffith; Inland area & Verox1 \\
\hline 4767 & 1990 & Cx annul & Wentworth; Inland area & Not recorded \\
\hline 14291 & 1992 & Cx annul & Griffith; Inland area & $\mathrm{BHK} 21 \times 1 \rightarrow \mathrm{BHK} 21 \times 1 \rightarrow \mathrm{C} 6 / 36 \times 1$ \\
\hline 28937 & 1994 & Cx annul & Boggabilla; Inland area & $\mathrm{C} 6 / 36 \times 1 \Rightarrow \mathrm{C} 6 / 36 \times 1 \Rightarrow \mathrm{BHK} 21 \times 1 \Rightarrow \mathrm{BHK} 21 \times 1$ \\
\hline 36750 & 1996 & Ae vigilax & Port Stephens; Coastal area & $\mathrm{PESK}^{*} \times 1 \Rightarrow \mathrm{PESK} \times 1 \rightarrow \mathrm{PESK} \times 1 \rightarrow \mathrm{C} 6 / 36 \times 1$ \\
\hline 53302 & 1999 & Ae vigilax & Port Stephens; Coastal area & $\mathrm{BHK} 21 \times 1 \rightarrow \mathrm{BHK} 21 \times 1 \rightarrow \mathrm{C} 6 / 36 \times 1$ \\
\hline 145290 & 2008 & Cx annul & Griffith; Inland area & Not recorded \\
\hline T48 & $\begin{array}{c}\text { Laboratory } \\
\text { adapted }\end{array}$ & & & \\
\hline
\end{tabular}

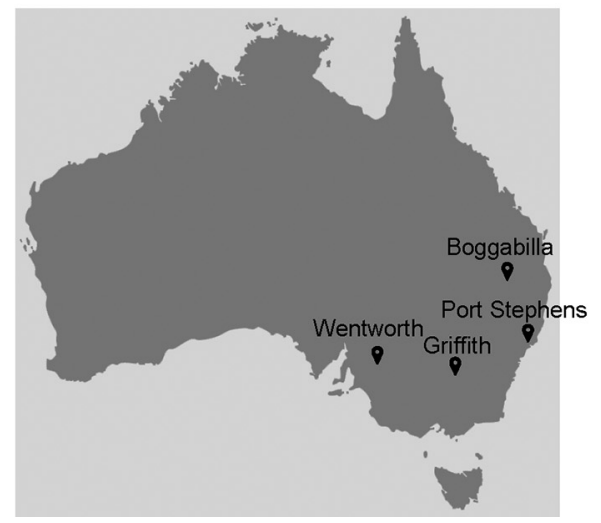

FIG 1 RRV field strains tested in the study. The RRV field strain, year it was isolated from the mosquito species, and trap location in Australia were recorded along with passage histories.

330 -fold growth inhibition compared to that of mock-treated controls. RRV 2548 IFN- $\beta$ sensitivity was significantly higher than that of any other field strain. For this reason, RRV 2548 was selected for further comparison with the prototype strain RRV-T48.

RRV 2548 has a reduced rate of replication compared to that of RRV-T48 in vitro. To determine the replication kinetics of RRV 2548 in vitro, multistep growth curves were produced in Vero, HeLa, and L929 cells. Cells were infected with either RRV-T48 or RRV 2548 at an MOI of 0.1 . Cell culture media were collected at 12, 24, 36, and $48 \mathrm{~h}$ p.i. and analyzed using a plaque assay. In Vero cells (Fig. 3A), RRV 2548 grew to significantly lower titers, $\sim 17$-fold and $\sim 5$-fold lower, than RRV-T48 at 24 and $36 \mathrm{~h}$ p.i., respectively. Although titers converged with no difference at $48 \mathrm{~h}$ p.i. In HeLa (Fig. 3B) and L929 (Fig. 3C) cells, the rate of infectious RRV 2548 production was consistently lower than RRV-T48, with significantly reduced titers at $36 \mathrm{~h}$ p.i. ( $\sim 9$-fold and $\sim 38$-fold lower, respectively). Thus, compared to RRV-T48, RRV 2548 displayed reduced growth in all three mammalian cell lines.

RRV 2548 infection induces high levels of type I IFN in L929 cells and exhibits enhanced sensitivity to human IFN- $\boldsymbol{\beta}$. To compare type I IFN induction following infection, L929 cells were infected with RRV-T48 and RRV 2548 at an MOI of 0.1. In parallel, as a positive control for IFN induction, cells were transfected with $10 \mu \mathrm{g}$ poly $(I \cdot C)$. Cell culture media were collected and UV inactivated $12 \mathrm{~h}$ and $24 \mathrm{~h}$ later, and type I IFN production was determined by performing a cytopathic effect (CPE) inhibition bioassay using SFV infection of 2929 cells. Transfection of poly(I.C) and infections with RRV-T48 and RRV 2548 all triggered type I IFN production to various degrees (Fig. 4A). RRV 2548 induced significantly higher levels of type I IFN than RRV-T48. On average, RRV 2548 induced approximately $830 \mathrm{IU} / \mathrm{ml}$ and $925 \mathrm{IU} / \mathrm{ml}$ of type I IFN at 12 $\mathrm{h}$ and $24 \mathrm{~h}$ p.i., respectively, compared to approximately $180 \mathrm{IU} / \mathrm{ml}$ and $585 \mathrm{IU} / \mathrm{ml}$ 


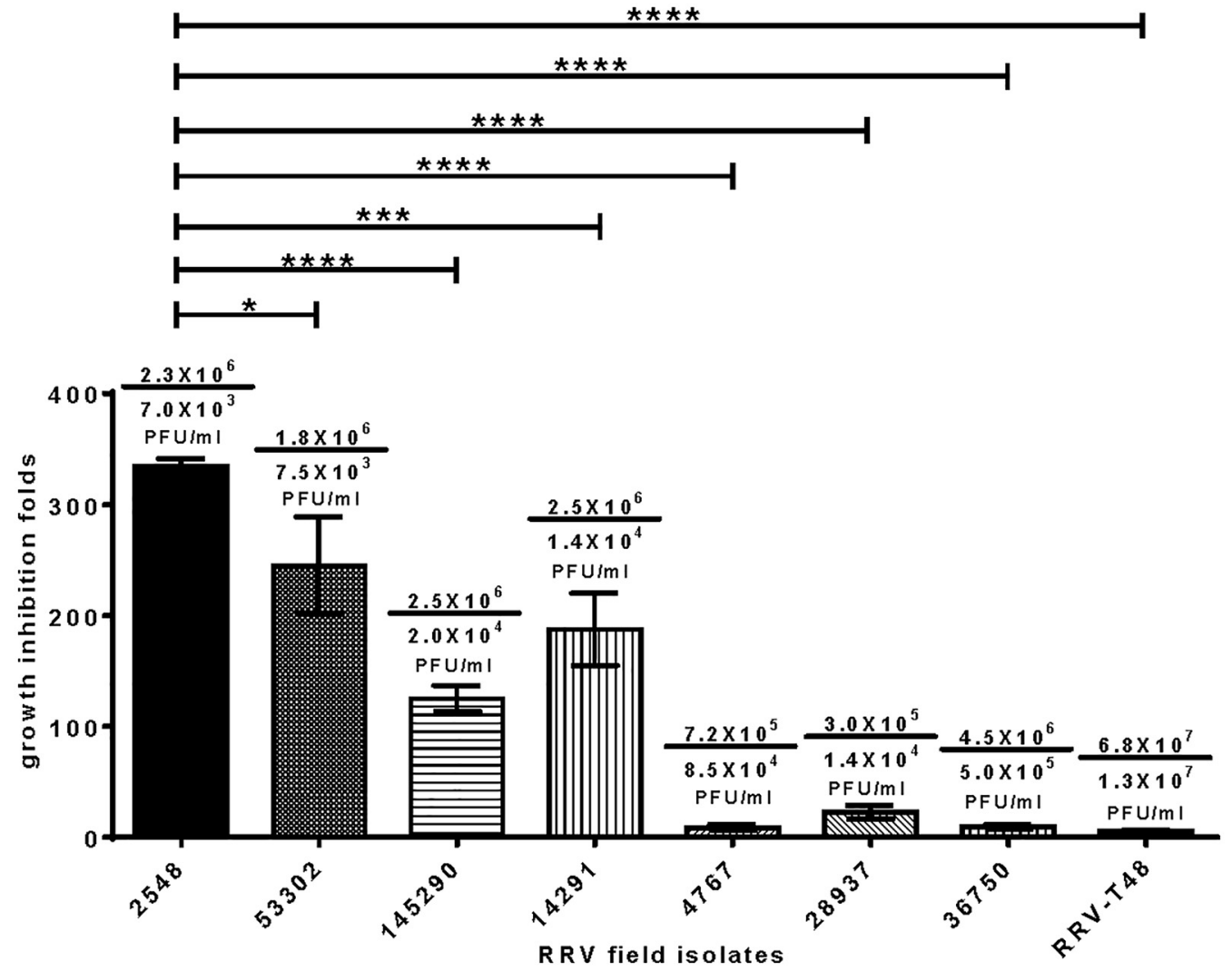

FIG 2 Type I IFN sensitivities of RRV-T48 and RRV field strains. Vero cells were treated with human IFN- $\beta$ at $0.05 \mathrm{ng} / \mathrm{ml}$; control cells were left untreated. The cells were then infected with RRV field strains and RRV-T48 at an MOI of 0.1. The cell culture media were collected at $24 \mathrm{~h}$ p.i. and analyzed by plaque assay. The numbers above each column represent the viral titer without/with IFN- $\beta$ treatment (average from three independent experiments). The sensitivity to type I IFN is represented by a decrease in viral titer by IFN- $\beta$ treatment. Error bars represent \pm standard errors of the means (SEMs) from three independent experiments. ${ }^{*}, P<0.05 ;{ }^{* * *}, P<0.001 ;{ }^{* * * *}, P<0.0001$ using one-way ANOVA with Bonferroni's post hoc test.

induced by RRV-T48 at the respective times. Thus, RRV 2548 also induced high levels of type I IFN earlier than RRV-T48.

To characterize and compare the type I IFN sensitivity of RRV 2548 and RRV-T48, Vero cells were treated with increasing amounts of human IFN- $\beta$ ranging from $0.05 \mathrm{ng} / \mathrm{ml}$ to $0.25 \mathrm{ng} / \mathrm{ml}$ and then infected with RRV-T48 or RRV 2548; control cells were mock treated. The supernatants were collected for plaque assay at $24 \mathrm{~h}$ p.i. The replication of both RRV-T48 and RRV 2548 was reduced with increasing concentrations of IFN- $\beta$ (Fig. 4B). However, growth inhibition of RRV 2548 was significantly greater than that of RRV-T48 at all concentrations of IFN- $\beta$ (Fig. 4B), reaching $\sim 390$-fold already at $0.05 \mathrm{ng} / \mathrm{ml} \mathrm{IFN}-\beta$. At $0.25 \mathrm{ng} / \mathrm{ml} \mathrm{IFN}-\beta$, RRV 2548 completely failed to replicate, as observed titer $\sim 10^{2} \mathrm{PFU} / \mathrm{ml}$ most likely originated from the remaining virus used in the inoculum. Together, the results suggest RRV 2548 is not only a stronger and earlier inducer of type I IFN but also has increased sensitivity to IFN- $\beta$ compared to that of RRV-T48.

RRV 2548 induces high levels of type I IFN in C57BL/6 mice. To assess the replication efficiency of RRV 2548 in vivo, twenty-day-old C57BL/6 wild-type (WT) mice were infected subcutaneously with $10^{4}$ PFU of RRV-T48 or RRV 2548. Mice were culled at $12,24,48$, and $72 \mathrm{~h}$ p.i., and serum, quadriceps, and spleens were collected for plaque assay analysis. At 24 and 48 h p.i., mice infected with RRV 2548 showed significantly reduced viremia compared to RRV-T48-infected mice (Fig. 5A). In the spleen, RRV-T48 titers peaked at 24 h p.i., while RRV 2548 titers peaked at 48 h p.i. (Fig. $5 B)$. The profile of infectious virus recovered from quadriceps showed significantly 

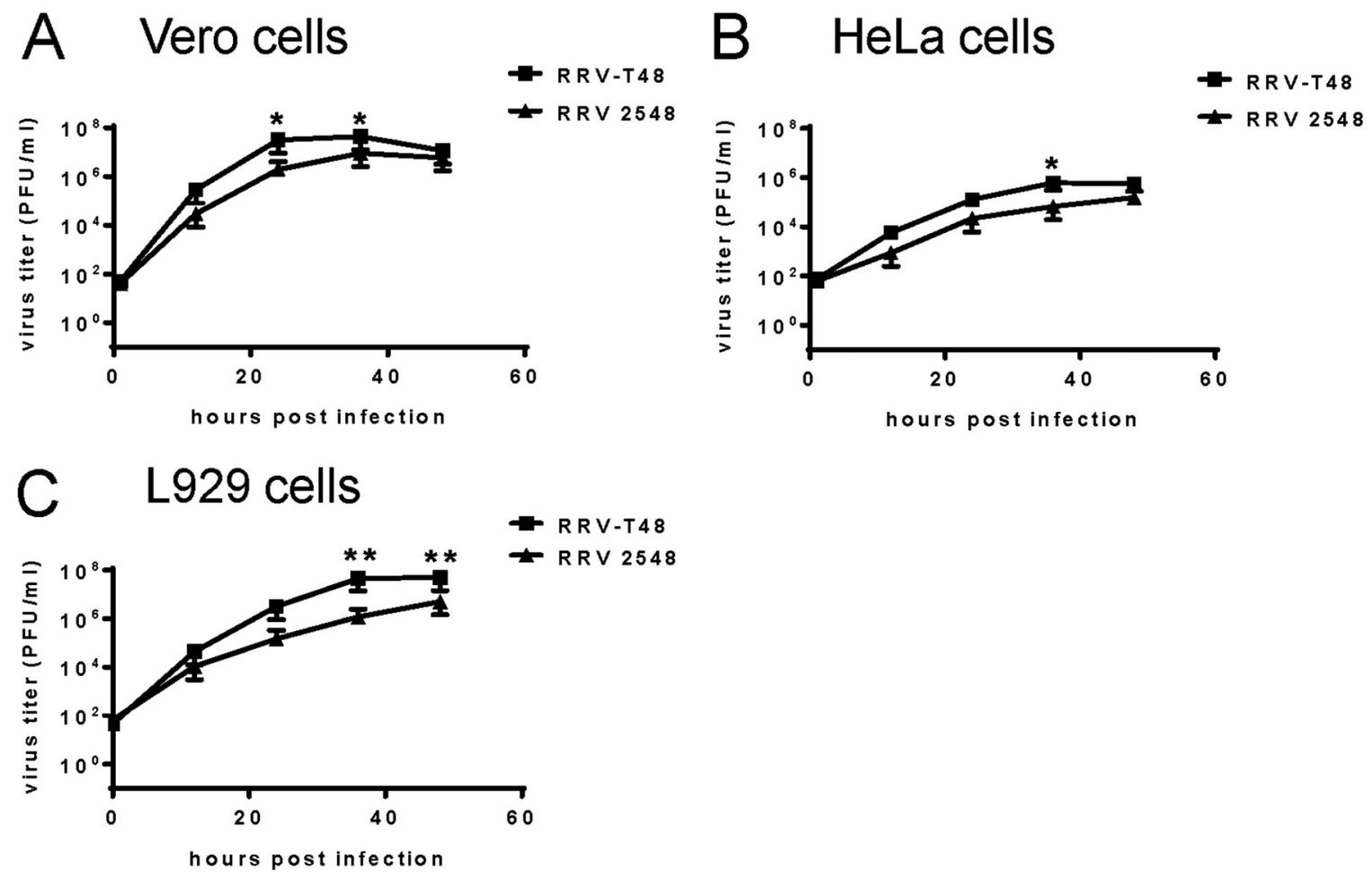

FIG 3 Multistep growth curves of RRV-T48 and RRV 2548. The growth kinetics of RRV-T48 or RRV 2548 were analyzed in Vero (A), HeLa (B), and L929 cells (C). Cells were infected with either RRV-T48 or RRV 2548 at an MOI of 0.1. All the cell culture media were collected at $12 \mathrm{~h}, 24 \mathrm{~h}, 36 \mathrm{~h}$, and $48 \mathrm{~h}$ p.i. and analyzed by plaque assay. The limit of detection was $30 \mathrm{PFU} / \mathrm{ml}$. Values are expressed as the mean titers \pm SEMs from three independent experiments. ${ }^{*}, P<0.05 ;{ }^{* *}, P<0.01$ using two-way ANOVA with Bonferroni's post hoc test.

reduced titers of RRV 2548 at $24 \mathrm{~h}$ p.i. compared to those in RRV-T48-infected mice (Fig. 5C). Thus, the replication profile of the two RRV strains differed in vivo, with RRV-T48 generally exhibiting more efficient replication.

To determine the level of type I IFN induced by RRV-T48 and RRV 2548 infection, IFN bioassays were performed using serum, spleens, and quadriceps of infected mice. Compared to RRV-T48, RRV 2548 induced $\sim 1.9$-fold higher levels of type I IFN in serum at $12 \mathrm{~h}$ p.i. and $\sim 2.1$-fold higher levels of type I IFN in the spleen at $24 \mathrm{~h}$ p.i. (Fig. 5D and E). In quadriceps, the levels of type I IFN induced by RRV 2548 and RRV-T48 infection peaked at $24 \mathrm{~h}$ p.i. (Fig. 5F). Although RRV 2548 induced larger amounts of type I IFN than RRV-T48 in quadriceps, the difference between the two strains was not statistically significant.

RRV 2548 induces milder disease than RRV-T48 in C57BL/6 mice. To investigate the inflammatory disease manifestations caused by infection with RRV 2548, C57BL/6 mice were subcutaneously infected with $10^{4}$ PFU of RRV-T48 or RRV 2548. Mockinfected control mice received PBS alone. Weights and disease signs were recorded daily. Compared to RRV 2548-infected mice, mice infected with RRV-T48 showed significantly reduced weight gain from day 7 p.i. (Fig. 6A). RRV-T48-infected mice developed severe hind limb weakness and loss of gripping ability. In contrast, mice infected with RRV 2548 developed milder hind limb weakness, which contributed to significantly lower disease scores than in RRV-T48-infected mice from day 7 to day 10 p.i. (Fig. 6B). At day 10 p.i., mice were culled, and quadriceps collected for histological analysis by hematoxylin and eosin (H\&E) staining. Histological analysis revealed that the quadriceps of RRV-T48-infected mice had greater signs of inflammation and muscle tissue damage than those of RRV 2548-infected mice (Fig. 6C). Furthermore, semiquantitative analysis of quadriceps immune cell infiltration showed that the number of cells in the muscle of RRV-T48-infected mice was $\sim 1.5$-fold higher than that measured in the quadriceps of mice infected with RRV 2548 (Fig. 6D). Taken together, these results 

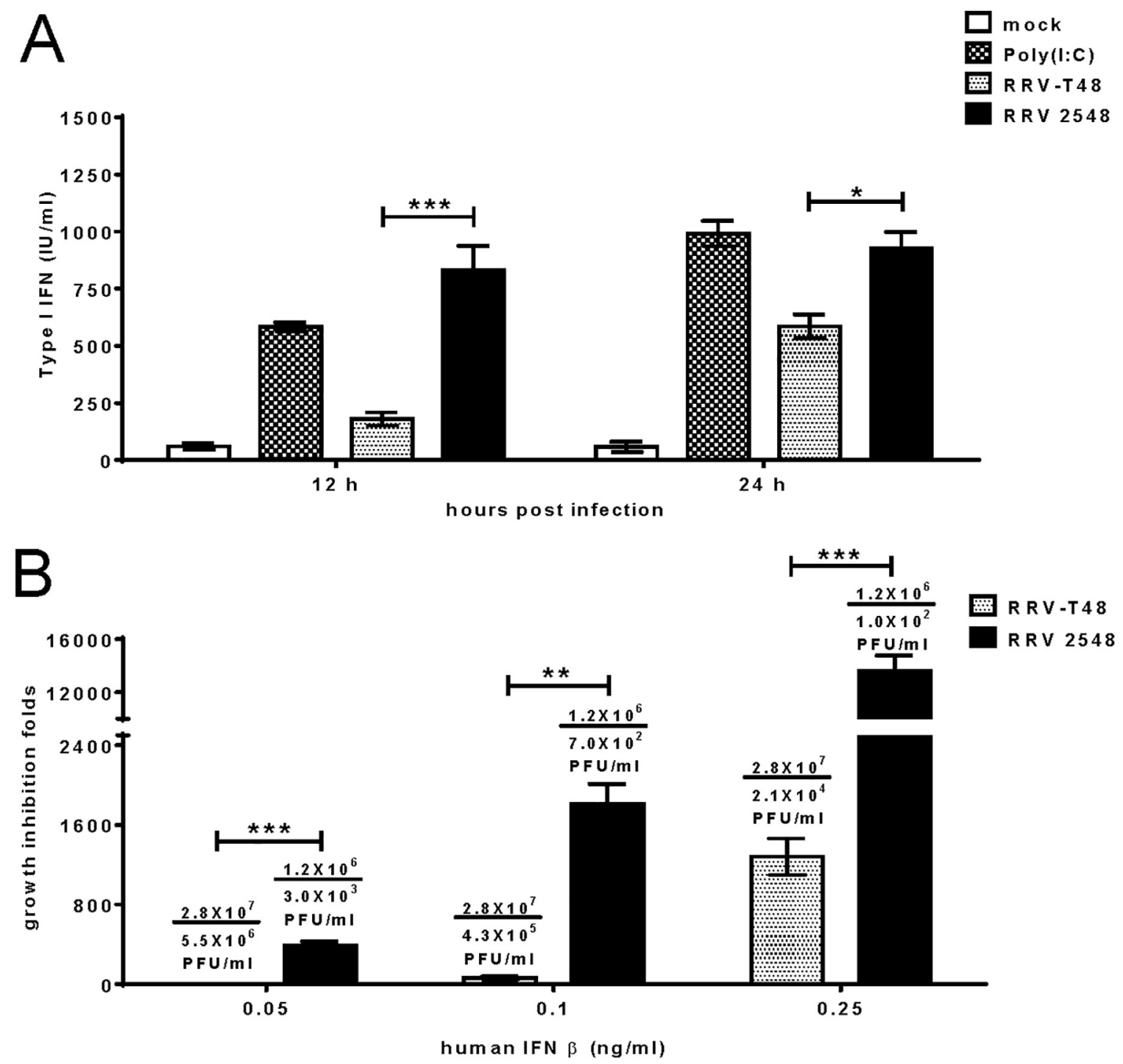

FIG 4 RRV 2548 type I IFN induction and sensitivity in vitro. L929 cells infected with either RRV-T48 or RRV 2548 at an MOI of 0.1 or transfected with poly(I.C) were sampled at $12 \mathrm{~h}$ and $24 \mathrm{~h}$ p.i. (A) Type I IFN levels in cell culture medium were determined by IFN bioassay. (B) Type I IFN sensitivities of RRV-T48 and 2548 were assessed by growth inhibition and are presented as described for Fig. 2 except that human IFN- $\beta$ was used at $0.05,0.1$, or $0.25 \mathrm{ng} / \mathrm{ml}$. Error bars represent \pm SEMs from three independent experiments. ${ }^{*}, P<0.05 ;{ }^{* \star *}, P<$ 0.001 using two-way ANOVA with Bonferroni's post hoc test $(\mathrm{A}) ;{ }^{* *}, P<0.01 ;{ }^{* *}, P<0.001$ using Student's unpaired $t$ test (B).

demonstrate that RRV 2548-infected mice developed less severe disease and displayed reduced inflammation in the quadriceps muscle than RRV-T48-infected mice.

RRV nsP1 and nsP2 play a major role in type I IFN modulation. The nsPs of RRV, CHIKV, SINV, and SFV were previously shown to play essential roles in type I IFN modulation $(12,13,23,26,27)$. Therefore, the sequence of the RRV 2548 nonstructural region was determined and compared to that of RRV-T48. In total, 221 nucleotide differences were revealed (Table 1). Most of these differences represented synonymous changes; however, there were 4 nonsynonymous substitutions in nsP1, 8 in nsP2, and 6 in nsP4. nsP3 of RRV 2548 contained, in addition to 12 nonsynonymous substitutions, a 12-amino-acid insertion (Table 2). To determine whether these mutations were responsible for the different type I IFN responses of RRV-T48 and RRV 2548, we designed and constructed two chimeric viruses, RRV M12 that contained the nsP1-nsP2 region from RRV 2548 and RRV M34 that had the nsP3-nsP4 region from RRV 2548 in the RRV-T48 backbone (Fig. 7A). Both chimeras were viable and replicated in L929 and Vero cells to similar levels. It was noticed, however, that the yields of the chimeric 

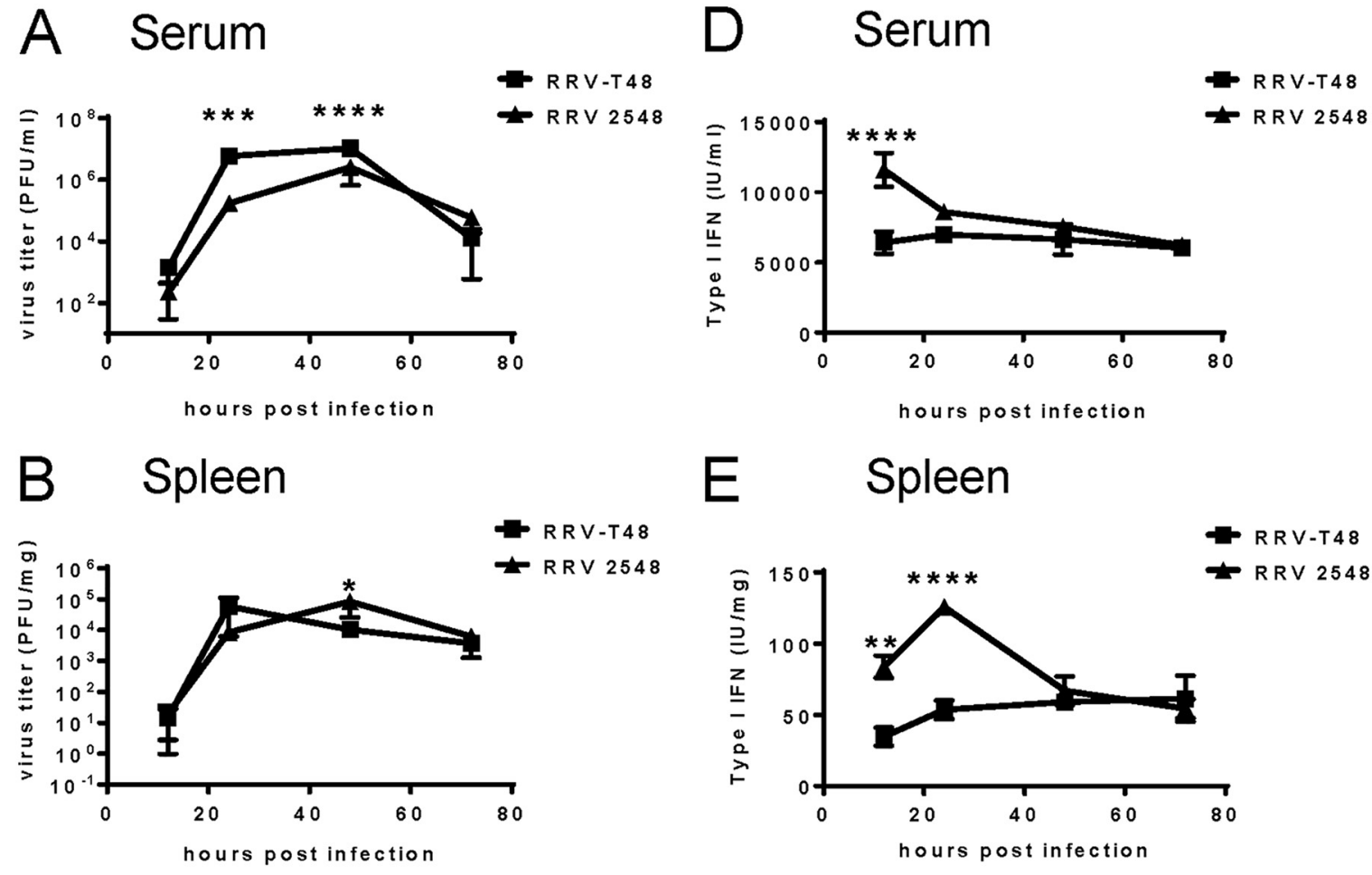

\section{Quadriceps}
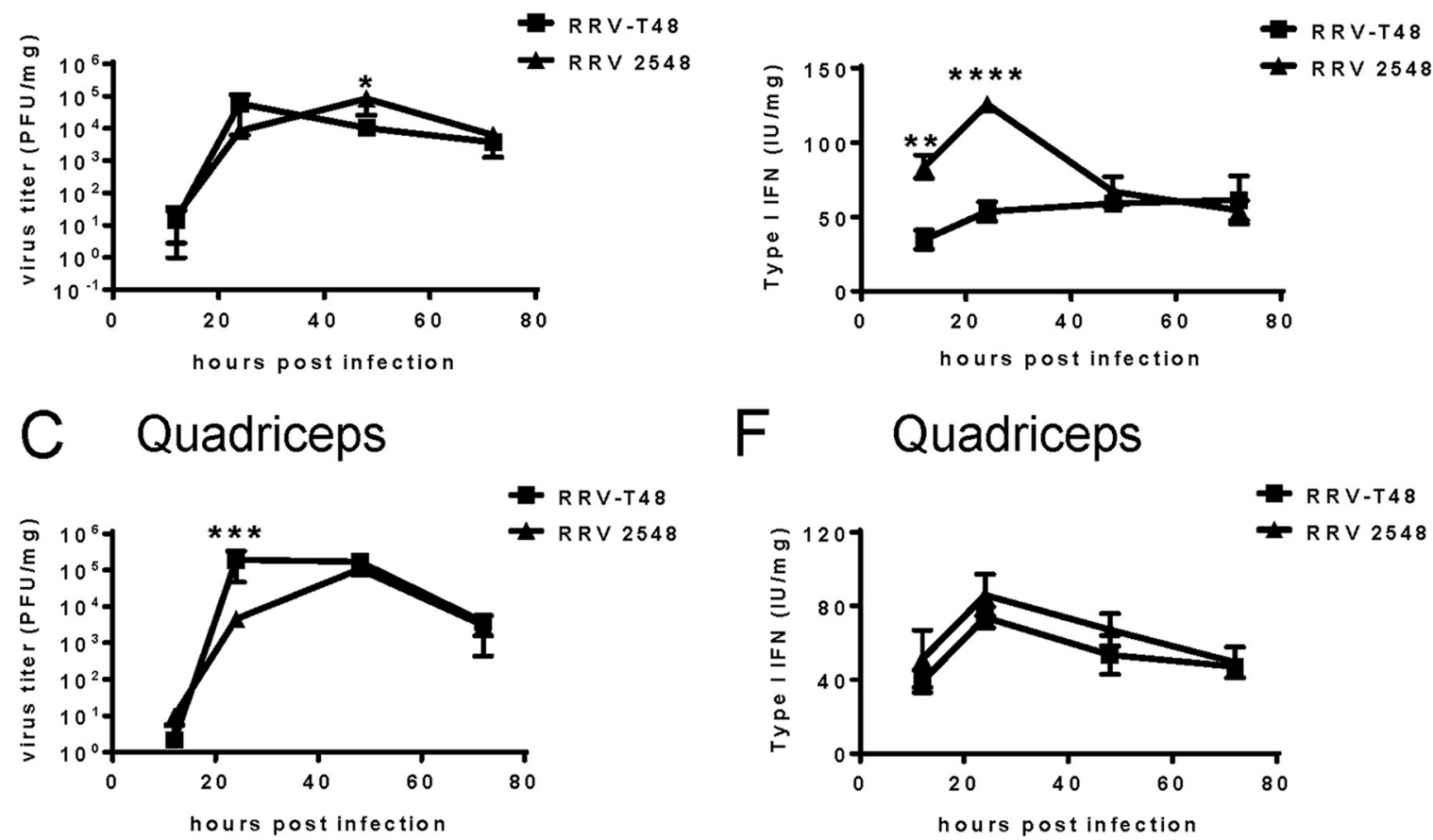

F Quadriceps

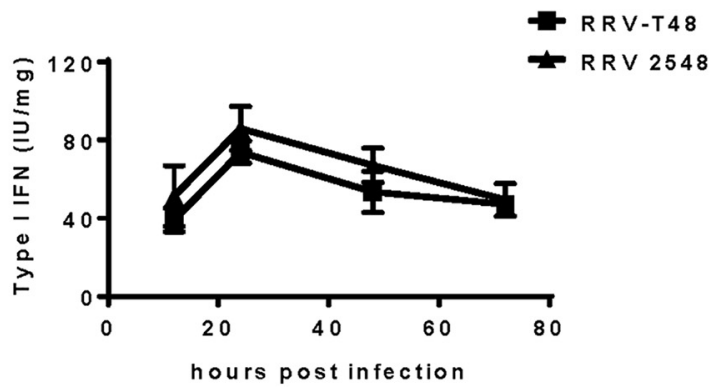

FIG 5 RRV 2548 replication and type I IFN induction in vivo. Twenty-day-old C57BL/6 WT mice (5 mice per group) were injected subcutaneously with $10^{4}$ PFU of RRV-T48 or RRV 2548. Animals were euthanized, and serum, spleens, and quadriceps were collected at 12 h, 24 h, 48 h, and 72 h p.i. Viral titers were determined by plaque assay for serum (A), spleen (B), and quadriceps (C), and type I IFN levels were measured by SFV bioassay for serum (D), spleen (E), and quadriceps (F). Values are shown as the means \pm SEMs from duplicate experiments. ${ }^{*}, P<0.01 ;{ }^{* *}, P<0.01 ;{ }^{* * *}, P<0.001 ;{ }^{* * * *}, P<0.0001$ using two-way ANOVA with Bonferroni's post hoc test.

viruses were significantly different. RRV M34 replicated to high titers that were comparable to those of RRV-T48. In contrast, RRV M12 replicated to lower titers similar to those of RRV 2548 in L929 but had higher titers than RRV 2458 in Vero cells (Fig. 7B). Next, the type I IFN induction abilities of RRV M12 and RRV M34 were investigated. Both chimeric viruses induced higher levels of type I IFN in 2929 cells than RRV-T48. Furthermore, RRV M12 induced significantly higher levels of type I IFN than RRV M34 or even RRV 2548 both at 12 and 24 h p.i. (Fig. 7C). A similar tendency was revealed for type I IFN sensitivity. Again, IFN- $\beta$ inhibited replication of both chimeric viruses to a larger extent than it inhibited replication of RRV-T48. Inhibition of RRV M12 replication was significantly more prominent than that of RRV M34 and, similarly to RRV 2548, RRV M12 most likely completely failed to replicate at $0.25 \mathrm{ng} / \mathrm{ml}$ IFN- $\beta$ (Fig. 7D). Therefore, it was concluded that the type I IFN modulation determinants of RRV 2548 were mostly associated with nsP1 and/or nsP2. The type I IFN modulation determinants of RRV 2548 associated with nsP1 and/or nsP2 were therefore mapped further. However, as RRV- 

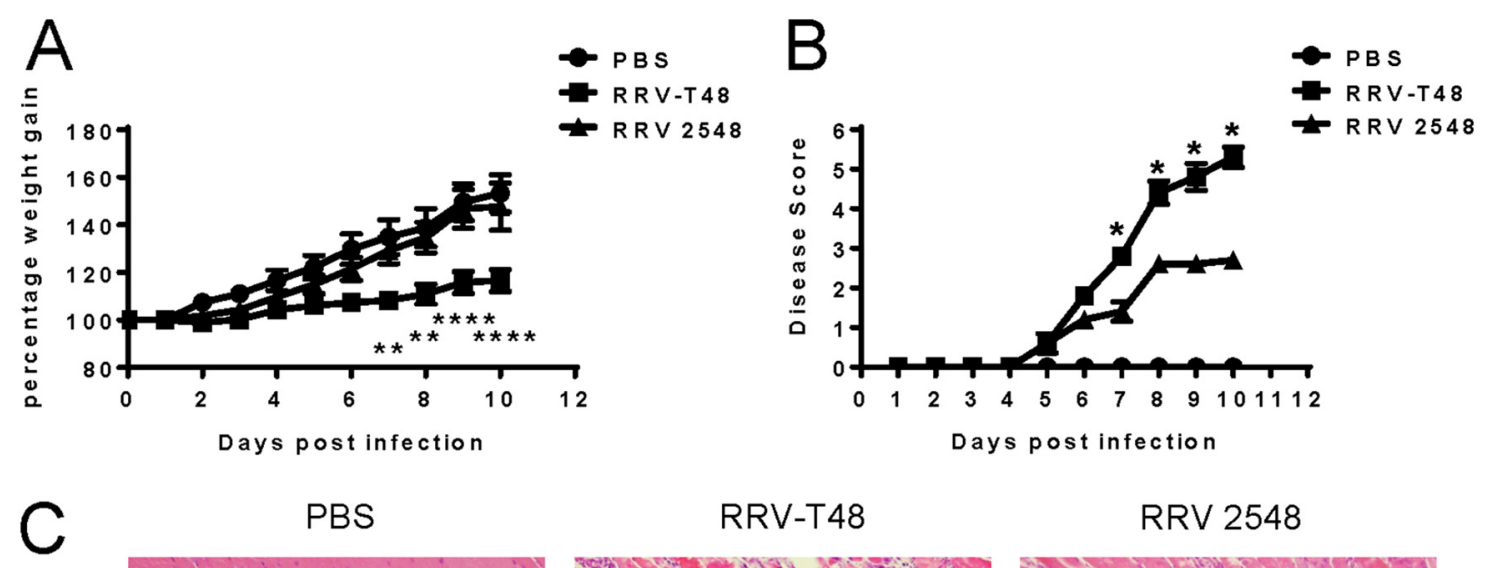

\section{PBS}

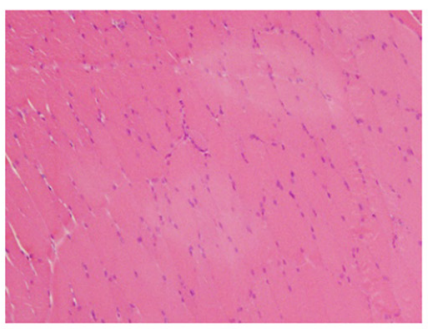

RRV-T48

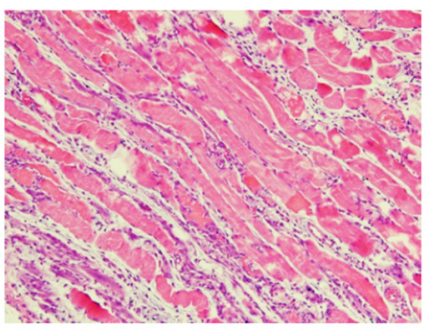

RRV 2548

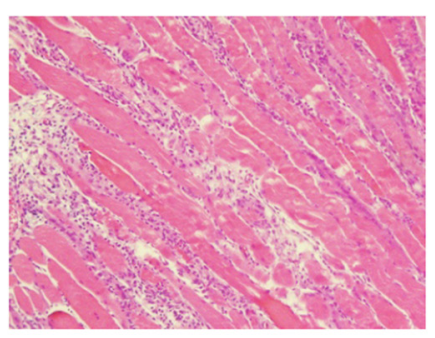

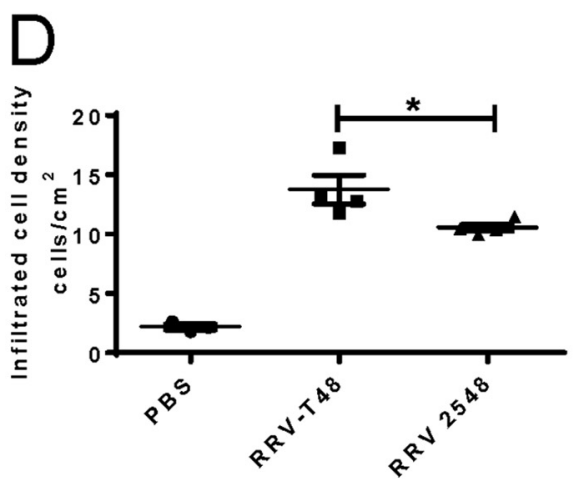

FIG 6 RRV 2548 infection causes milder disease and reduced inflammatory cell infiltration in mice. Twenty-day-old C57BL/6 WT mice were injected subcutaneously with $10^{4}$ PFU RRV-T48 or RRV 2548. Mouse weights (A) and clinical scores (B) were monitored daily. Mice were scored according to hindlimb strength and onset of hindlimb dysfunction. Mock-infected mice showed no disease signs for the duration of the experiment. (C) Quadriceps were collected on day 10 p.i., fixed in $4 \%$ paraformaldehyde, paraffin embedded, cut into $5-\mu \mathrm{m}$ sections, and stained with H\&E. Images are shown at $\times 100$ magnification. (D) The numbers of infiltrated inflammatory cells were quantified using image J. (A, B, and D) All values represent the means \pm SEMs from 5 mice per group in duplicate experiments. Shown statistical significance always applies to the differences measured between RRV-T48- and RRV 2548-infected mice. ${ }^{* *}, P<0.01 ;{ }^{* * * *}$, $P<0.0001$ using two-way ANOVA with Bonferroni's posttest (A); ${ }^{*}, P<0.05$ using nonparametric Mann-Whitney test $(\mathrm{B}) ;{ }^{*}, P<0.05$ using Student's unpaired $t$ test (D).

M34 was also more type I IFN sensitive than RRV-T48, some determinants of type I IFN sensitivity were likely located in nsP3 and/or nsP4.

Mapping of determinants of RRV 2548 type I IFN modulation. From all amino acid substitutions detected in the nsP1-nsP2 region of RRV 2548, V186A, E402A, and

TABLE 1 Comparison of nucleic acid sequences of nonstructural regions of RRV 2548 and RRV-T48

\begin{tabular}{lll}
\hline nsP gene & Length (bp) & No. of substitutions \\
\hline$n s P 1$ & 1,602 & 31 \\
$n s P 2$ & 2,394 & 51 \\
$n s P 3$ & 1,614 (RRV-T48) & 94 \\
& $1,650^{a}$ (RRV 2548) & 45 \\
nsP4 & 1833 & 4 \\
\hline
\end{tabular}

aThere is a 36-bp insertion in $n s P 3$ gene of RRV 2548. 
TABLE 2 Comparison of amino acid sequences of nonstructural regions of RRV 2548 and RRV-T48

\begin{tabular}{llll}
\hline & & $\begin{array}{l}\text { No. of } \\
\text { nsP }\end{array}$ & Length (aa) \\
substitutions & Substitutions (RRV-T48 to 2548) \\
\hline nsP1 & 534 & 4 & V186A, I278V, E402A, R522Q \\
nsP2 & 798 & 8 & R11K, A31T, E116D, V123I, E167D, N219T, S580L, Q619R \\
nsP3 & 538 (RRV-T48) & $12^{b}$ & T28A, Q59R, N279S, K323Q, T331M, RADTVSLDSSVL \\
& & & 332-343 (insertion) \\
& 550 (RRV 2548) & & V419A, E436G, K439T, C505R, K506E, V520I, S530P \\
nsP4 & 611 & 6 & V41A, T98I, K106R, R116L, L235F, V450I \\
\hline
\end{tabular}

$a_{\text {aa, amino acids. }}$

${ }^{b}$ There is a 12-amino-acid insertion in nsP3 of RRV 2548.

R522Q in nsP1 and A31T, N219T, S580L, and Q619R in nsP2 were assessed as significant differences based on the change in charge, steric hindrance, and hydrophobic index of these amino acid residues (Table 3). With the exception of nsP1 E402A, all these substitutions were found to be common in different isolates of RRV and, interestingly, often occur in combinations similar to these found in RRV 2548 (Table 4). To further define if these substitutions represent novel type I IFN determinants, seven mutant RRV-T48 infectious clones, each harboring a single mutation in nsP1 or nsP2, were constructed (Fig. 8A). All mutant viruses were successfully rescued. In contrast to RRV M12 (Fig. 7B) and RRV 2548, they were all able to replicate in L929 cells to titers of $>10^{7}$ $\mathrm{PFU} / \mathrm{ml}$ (Fig. 8B). Next, the type I IFN induction abilities of these seven viruses were determined. Compared to RRV-T48, viruses harboring substitutions S580L and Q619R in nsP2 induced significantly higher levels of type I IFN at 24 h p.i. (Fig. $8 C$ ). In contrast, none of the mutants harboring substitutions in nsP1 produced elevated type I IFN levels (Fig. 8C). However, when the type I IFN sensitivities of these mutants were determined, a similar trend was not observed. Compared with RRV-T48, mutant viruses with substitutions E402A and R522Q in nsP1 and Q619R in nsP2 exhibited enhanced growth inhibition in the presence of human IFN- $\beta$ at a concentration of $0.25 \mathrm{ng} / \mathrm{ml}$ (Fig. $8 D)$. Furthermore, all viruses with substitutions in nsP1 and virus with nsP2 Q619R substitution demonstrated statistically significant enhanced growth inhibition compared to that of RRV-T48 already at $0.1 \mathrm{ng} / \mathrm{ml} \mathrm{IFN-} \beta$ (Fig. 8D). These results indicate that all seven residues of RRV-T48 are involved in generating the resistance to type I IFN. The impact of V186, E402, and R522 in nsP1 and Q619 in nsP2 was most prominent, as substitution of any of these residues alone resulted, in the presence of IFN- $\beta$, in titers coherent with complete lack of replication, e.g., they had a phenotype similar to that of RRV-M12 harboring all these changes combined.

Interferon sensitivity of RRV recombinants and mutants does not correlate with general shutoff of cellular translation. We have previously demonstrated that RRV-T48 infection results in complete shutoff of host cell translation in BHK-21 cells (23). To determine the effect of RRV recombinants and mutants on host cell protein synthesis, similar experiments were performed. In BHK-21 cells lacking a functional type I IFN system $(28,29)$, RRV recombinants and all RRV mutants were capable of inducing near-complete shutoff of host cell translation by $24 \mathrm{~h}$ p.i.; no clear differences from RRV-T48 were observed at any time point (Fig. 9A). These results suggest that enhanced IFN induction/sensitivity of RRV recombinants and mutants may be due to a more specific mechanism rather than general protein shutoff. A slight reduction in the level of structural polyprotein of RRV M12 suggests that RRV M12 has reduced replicative capacity compared to those of RRV-T48 and recombinant RRV M34 (Fig. 7B).

It has been demonstrated by us and others that defects of nonstructural polyprotein processing can also result in increased induction of type I IFN $(14,17,23)$. Albeit none of the seven mutations found in RRV 2548 is associated with polyprotein cleavage sites or known determinants of nsP2 protease activity, we analyzed nonstructural polyprotein processing in a cell-free system. Results of this analysis confirmed that all RRV recombinants and mutants were able to process the nonstructural polyprotein as 
A RRV 2548 genome RNA cap

Poly(A)

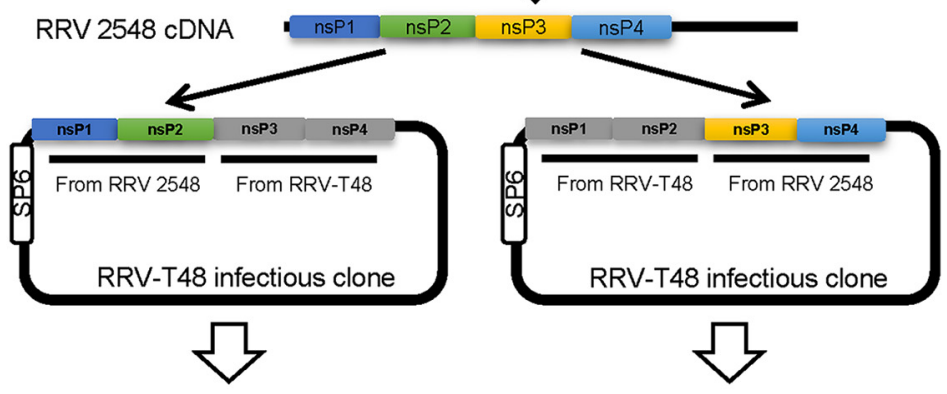

RRV M12

RRV M34

$B$

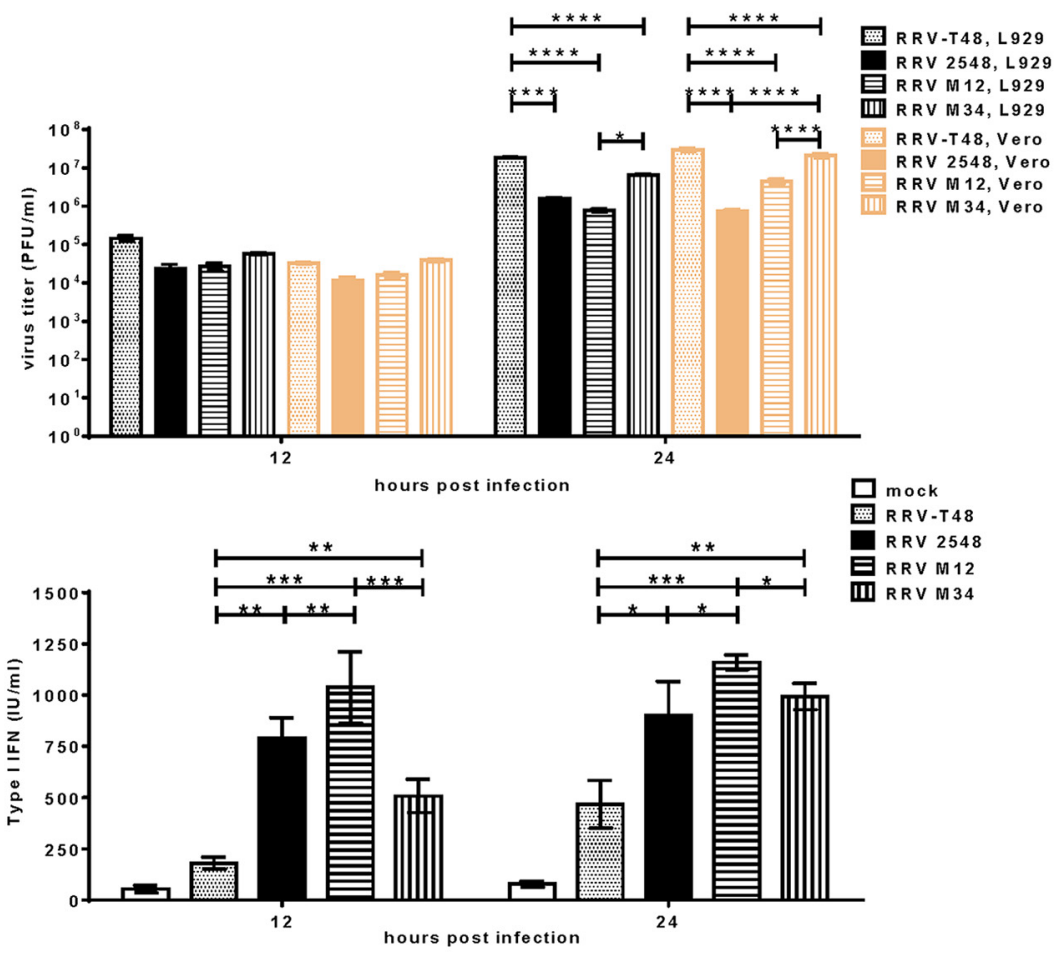

$\mathrm{D}$

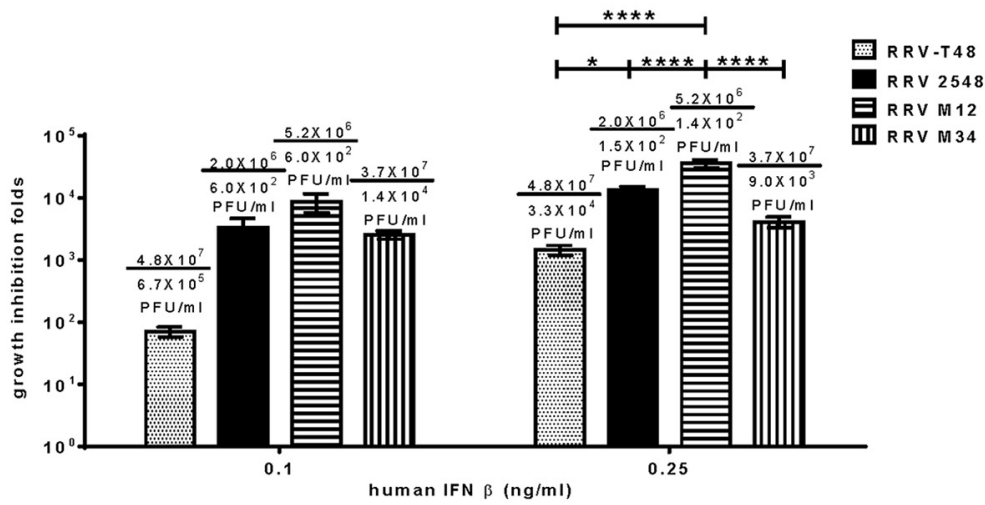

FIG 7 Type I IFN modulation of chimeric RRVs. (A) The chimeric RRV M12 and M34 were constructed as shown. (B) Vero and L929 cells were infected with RRV-T48, RRV 2548, RRV M12, and RRV M34 at an MOI of 2 , and cell culture media were collected at 12 and $24 \mathrm{~h}$ p.i. for analysis by plaque assay. The type I IFN induction (C) and sensitivity (D) of RRV-T48, RRV 2548, RRV M12, and RRV M34 were determined as described for Fig. $4 A$ and $B$, respectively. Error bars represent \pm SEMs from three independent experiments. ${ }^{*}, P<0.05 ;{ }^{* *}, P<0.01 ;{ }^{* * *}, P<0.001 ;{ }^{* * * *}, P<0.0001$ using two-way ANOVA with Bonferroni's post hoc test $(B$ and $C) ;{ }^{*}, P<0.05 ;{ }^{* * * *}, P<0.0001$ using one-way ANOVA with Bonferroni's post hoc test (D). 
TABLE 3 Significant substitutions in nsP1-nsP2 regions of RRV 2548 compared to those of RRV-T48

\begin{tabular}{|c|c|c|c|c|c|c|}
\hline $\mathrm{NsP}$ & $\begin{array}{l}\text { Substitutions } \\
\text { (RRV-T48 to 2548) }\end{array}$ & $\begin{array}{l}\text { Amino } \\
\text { acid }\end{array}$ & $\begin{array}{l}\text { Charge } \\
\text { at pH } 7.0\end{array}$ & $\begin{array}{l}\text { Side chain mol wt } \\
\text { (steric hindrance) }\end{array}$ & $\begin{array}{l}\text { Hydrophobic } \\
\text { index }\end{array}$ & $\begin{array}{l}\text { Substitution } \\
\text { significance }^{a}\end{array}$ \\
\hline \multirow[t]{5}{*}{ nsP1 } & V186A & $\mathrm{V}$ & Nonpolar & 99.14 & 76 & Yes \\
\hline & & A & Nonpolar & 71.09 & 41 & \\
\hline & & V & Nonpolar & 99.14 & 76 & \\
\hline & E402A & $\mathrm{E}$ & Acidic & 129.12 & -31 & Yes \\
\hline & & $A$ & Nonpolar & 71.09 & 41 & \\
\hline \multirow[t]{12}{*}{ nsP2 } & $\mathrm{R} 11 \mathrm{~K}$ & $\mathrm{R}$ & Basic & 156.19 & -14 & No \\
\hline & & K & Basic & 128.17 & -23 & \\
\hline & $\mathrm{A} 31 \mathrm{~T}$ & $A$ & Nonpolar & 71.09 & 41 & Yes \\
\hline & & $\mathrm{T}$ & Polar & 101.11 & 13 & \\
\hline & E116D & $\mathrm{E}$ & Acidic & 129.12 & -31 & No \\
\hline & & D & Acidic & 115.09 & -55 & \\
\hline & N219T & $\mathrm{N}$ & Polar & 114.11 & -28 & Yes \\
\hline & & $\mathrm{T}$ & Polar & 101.11 & 13 & \\
\hline & S580L & $S$ & Polar & 87.08 & -5 & Yes \\
\hline & & L & Nonpolar & 113.16 & 97 & \\
\hline & Q619R & Q & Polar & 128.14 & -10 & Yes \\
\hline & & $\mathrm{R}$ & Basic & 156.19 & -14 & \\
\hline
\end{tabular}

aThe significance of the differences between nsP1-nsP2 regions of RRV 2548 and RRV-T48 was assessed based on the charge, hindrance steric, and hydrophobic index (67) of the amino acid residues located in variable positions. The substitutions assessed as significant have at least one notable change in the three factors.

efficiently as RRV-T48 (Fig. 9B), indicating that the enhanced type I IFN induction and sensitivity to IFN- $\beta$ were not due the differences in processing.

RIG-I and phosphorylated IRF3 are differentially regulated during infection with recombinant RRV mutants. To further investigate the mechanism of increased IFN induction by RRV strains, recombinants, and variants harboring point mutations, the expression of type I IFN-inducible proteins during infection was examined by Western blotting. No difference in expression levels of MDA5, IPS-1, TRAF3, TBK1, IRF3, IRF7, STAT1, or STAT2 was observed. In contrast, the levels of RIG-I were reproducibly higher in RRV 2548-infected cells than in RRV-T48-infected cells (Fig. 10). RIG-I expression was also notably increased in cells infected with RRV M12 or with RRV-T48 point mutants, with the exception of virus harboring nsP1 E402A substitution (Fig. 10). Additionally, RRV 2548, RRV M12, RRV M34, and RRV mutants harboring an nsP1 V186A, nsP2 A31T, or nsP2 N219T substitution induced higher levels of IRF3 phosphorylation than RRV-T48 in infected cells. Interestingly, IKK-i was found to be upregulated by only nsP1 R522Q, suggesting this substitution may modulate type I IFN induction, increasing its IFN sensitivity. RRV 2548-infected cells also showed prominently increased STAT1 phosphorylation compared to that in cells infected with RRV-T48. Compared to that in cells infected with RRV-T48, STAT1 phosphorylation was also increased in cells infected by all RRV recombinants and variants harboring point mutations. However, the observed increase was minor and not to the levels seen in RRV 2548-infected cells. In contrast, no prominent increase in STAT2 phosphorylation was observed in cells infected by any of the analyzed viruses. STAT2 phosphorylation was only slightly increased in RRV 2548-, RRV M12-, and RRV nsP2 Q619R-infected cells compared to that in RRV-T48-infected cells (Fig. 10). These results suggest that increased RIG-I expression and/or IRF3 phosphorylation may play a role in the enhanced IFN induction and/or sensitivity of RRV harboring nsP1 V186A, nsP2 A31T, nsP2 N219T, nsP2 S580L, or nsP2 Q619R substitutions. STAT1 and STAT2 phosphorylation during RRV 2548 infection may also contribute to enhanced IFN induction. 
TABLE 4 Sequence variability analysis at the seven positions in RRV nsP1 and nsP2 across the isolates

\begin{tabular}{|c|c|c|c|c|c|c|c|}
\hline RRV type & nsP1 186 & nsP1 402 & nsP1 522 & nsP2 31 & nsP2 219 & nsP2 580 & nsP2 619 \\
\hline RRV-T48 & V & $E$ & $\mathrm{R}$ & $A$ & $\mathrm{~N}$ & $\mathrm{~S}$ & Q \\
\hline RRV 2548 & A & A & Q & $\mathrm{T}$ & $\mathrm{T}$ & $\mathrm{L}$ & $\mathrm{R}$ \\
\hline RRV-1959-T48 & V & $E$ & $\mathrm{R}$ & A & $\mathrm{N}$ & $S$ & Q \\
\hline RRV-2975 & V & $E$ & $\mathrm{R}$ & A & $\mathrm{N}$ & $\mathrm{S}$ & Q \\
\hline RRV-3078 & V & $E$ & $\mathrm{R}$ & $A$ & $\mathrm{~N}$ & $S$ & Q \\
\hline RRV-2982 & V & $E$ & $\mathrm{R}$ & A & $\mathrm{N}$ & $\mathrm{S}$ & Q \\
\hline RRV-14389 & V & $E$ & $\mathrm{R}$ & $A$ & $\mathrm{~N}$ & $\mathrm{~S}$ & $\mathrm{R}$ \\
\hline RRV-9057 & V & $E$ & $\mathrm{R}$ & A & $\mathrm{N}$ & $\mathrm{S}$ & $\mathrm{R}$ \\
\hline RRV-8961 & V & $E$ & $\mathrm{R}$ & $A$ & $\mathrm{~N}$ & $\mathrm{~S}$ & $\mathrm{R}$ \\
\hline RRV-K3011 & V & $\mathrm{E}$ & $\mathrm{R}$ & $\mathrm{T}$ & $\mathrm{N}$ & $\mathrm{S}$ & Q \\
\hline RRV-1503 & V & $E$ & $\mathrm{R}$ & $\mathrm{T}$ & $\mathrm{N}$ & $\mathrm{S}$ & Q \\
\hline RRV-SW38788 & V & $\mathrm{E}$ & $\mathrm{R}$ & $\mathrm{T}$ & $\mathrm{N}$ & $\mathrm{S}$ & Q \\
\hline RRV-SW24336 & V & $E$ & $\mathrm{R}$ & $\mathrm{T}$ & $\mathrm{N}$ & $\mathrm{S}$ & Q \\
\hline RRV-SW12358 & V & $\mathrm{E}$ & $\mathrm{R}$ & $\mathrm{T}$ & $\mathrm{N}$ & $\mathrm{S}$ & Q \\
\hline RRV-SW11747 & V & $E$ & $\mathrm{R}$ & $\mathrm{T}$ & $\mathrm{N}$ & $\mathrm{S}$ & Q \\
\hline RRV-SW3181 & V & $\mathrm{E}$ & $\mathrm{R}$ & $\mathrm{T}$ & $\mathrm{N}$ & $\mathrm{S}$ & Q \\
\hline RRV-NB5092 & V & $E$ & Q & $\mathrm{T}$ & $\mathrm{N}$ & $\mathrm{S}$ & $\mathrm{R}$ \\
\hline RRV-NC_001511 & V & $\mathrm{E}$ & Q & $\mathrm{T}$ & $\mathrm{N}$ & $\mathrm{S}$ & $\mathrm{R}$ \\
\hline RRV-PW14 & A & $E$ & Q & $\mathrm{T}$ & $\mathrm{N}$ & $L$ & $\mathrm{R}$ \\
\hline RRV-MIDI13 & A & $\mathrm{E}$ & Q & $\mathrm{T}$ & $\mathrm{N}$ & $L$ & $\mathrm{R}$ \\
\hline RRV-MIDI86 & A & $E$ & Q & $\mathrm{T}$ & $\mathrm{N}$ & $\mathrm{L}$ & $\mathrm{R}$ \\
\hline RRV-MIDI32 & $A$ & $E$ & Q & $\mathrm{T}$ & $\mathrm{N}$ & $\mathrm{L}$ & $\mathrm{R}$ \\
\hline RRV-TT & A & $\mathrm{E}$ & Q & $\mathrm{T}$ & $\mathrm{N}$ & $L$ & $\mathrm{R}$ \\
\hline RRV-QML 1 & $A$ & $E$ & Q & $\mathrm{T}$ & $\mathrm{N}$ & $\mathrm{L}$ & $\mathrm{R}$ \\
\hline RRV-P6179 & A & $\mathrm{E}$ & Q & $\mathrm{T}$ & $\mathrm{N}$ & $\mathrm{L}$ & $\mathrm{R}$ \\
\hline RRV-P1373 & $A$ & $E$ & Q & $\mathrm{T}$ & $\mathrm{N}$ & $L$ & $\mathrm{R}$ \\
\hline RRV-P42273 & A & $\mathrm{E}$ & Q & $\mathrm{T}$ & $\mathrm{T}$ & $L$ & $\mathrm{R}$ \\
\hline RRV-P42213 & A & $E$ & Q & $\mathrm{T}$ & $\mathrm{T}$ & $\mathrm{L}$ & $\mathrm{R}$ \\
\hline RRV-P42161 & $A$ & $E$ & Q & $\mathrm{T}$ & $\mathrm{T}$ & $\mathrm{L}$ & $\mathrm{R}$ \\
\hline RRV-P42134 & A & $\mathrm{E}$ & Q & $\mathrm{T}$ & $\mathrm{T}$ & $L$ & $\mathrm{R}$ \\
\hline RRV-P42115 & $A$ & $E$ & Q & $\mathrm{T}$ & $\mathrm{T}$ & $\mathrm{L}$ & $\mathrm{R}$ \\
\hline RRV-K2505 & A & $E$ & Q & $\mathrm{T}$ & $\mathrm{T}$ & $\mathrm{L}$ & $\mathrm{R}$ \\
\hline
\end{tabular}

\section{DISCUSSION}

The type I IFN system is a crucial component of the innate immune system, providing defense against viral invasion. Alphaviruses are sensitive to type I IFN (30-32), and mice deficient in IFN- $\alpha / \beta$ receptor are highly susceptible to SINV, CHIKV, and VEEV infection (16, 33-35). However, alphaviruses, like many other viruses, have an ability to counteract the type I IFN system $(15,19,36,37)$. These type I IFN interference strategies can be loosely grouped as follows: (i) induction of general shutoff of cellular gene expression; (ii) specific virally encoded mediators, such as IFN antagonists (15); (iii) vector-derived immunosuppressive mediators (e.g., mosquito and tick saliva) that limit host responses against the invertebrate vector and also benefit the transmitted pathogen (36); and (iv) variations in viral glycosylation (37). Furthermore, viruses can use RNA structural motifs to avoid immune restriction (38).

For RRV, the mechanism of type I IFN modulation is still unclear. Mutations in the nsP1 region affect the ability of RRV to induce and counteract type I IFNs (14) and also affect its virulence in mice $(14,39)$. However, these studies were performed using laboratory-generated mutations and/or laboratory-adapted RRV strains. In the present study, seven previously uncharacterized RRV field strains were shown to possess different levels of sensitivity to type I IFN. Among these field strains, RRV 2548 was highly sensitive to type I IFN. Compared to RRV-T48, RRV 2548 replicated to lower titers in both type I IFN-competent cells and Vero cells unable to produce IFN $(40,41)$. Hence, the reduced in vitro replication of RRV 2548 may be influenced by, but is not solely dependent on, increased induction/sensitivity to type I IFNs. Notably, however, in L929 cells, RRV 2458 induced high levels of IFN at early stages of infection, with no or minimal increase of IFN levels at later stages. In contrast, RRV-T48-infected cells showed lower levels of IFN at early stages postinfection that increased at later stages (Fig. 4A). 

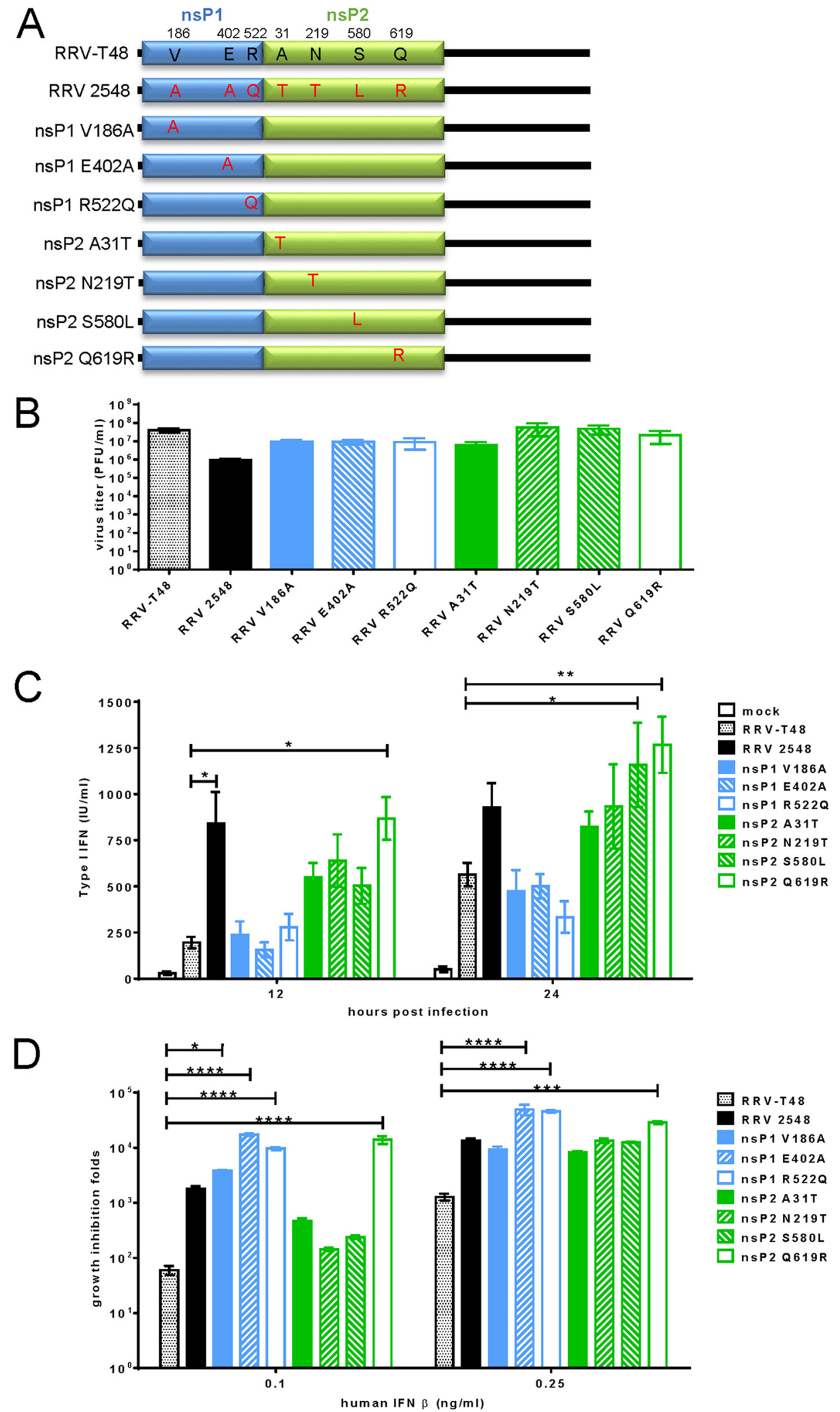

FIG 8 Type I IFN modulation of RRV-T48 mutants. (A) Mutations corresponding to significant changes found in RRV 2548 sequence were introduced into the RRV-T48 backbone. (B) Vero cells were infected with RRV-T48, RRV 2548, and indicated RRV-T48 mutants at an MOI of 2; cell culture media were collected at $24 \mathrm{~h}$ p.i. for plaque assay. The type I IFN inductions (C) and sensitivities (D) of analyzed viruses were determined as described for Fig. 4A and B. Error bars represent \pm SEMs from three independent experiments. ${ }^{*}, P<0.05 ;{ }^{* *}$, $P<0.01$ using two-way ANOVA with Bonferroni's post hoc test $(C) ;{ }^{*}, P<0.05 ;{ }^{* * *}, P<0.001 ;{ }^{* * * *}, P<0.0001$ using one-way ANOVA with Bonferroni's post hoc test (B and D). 

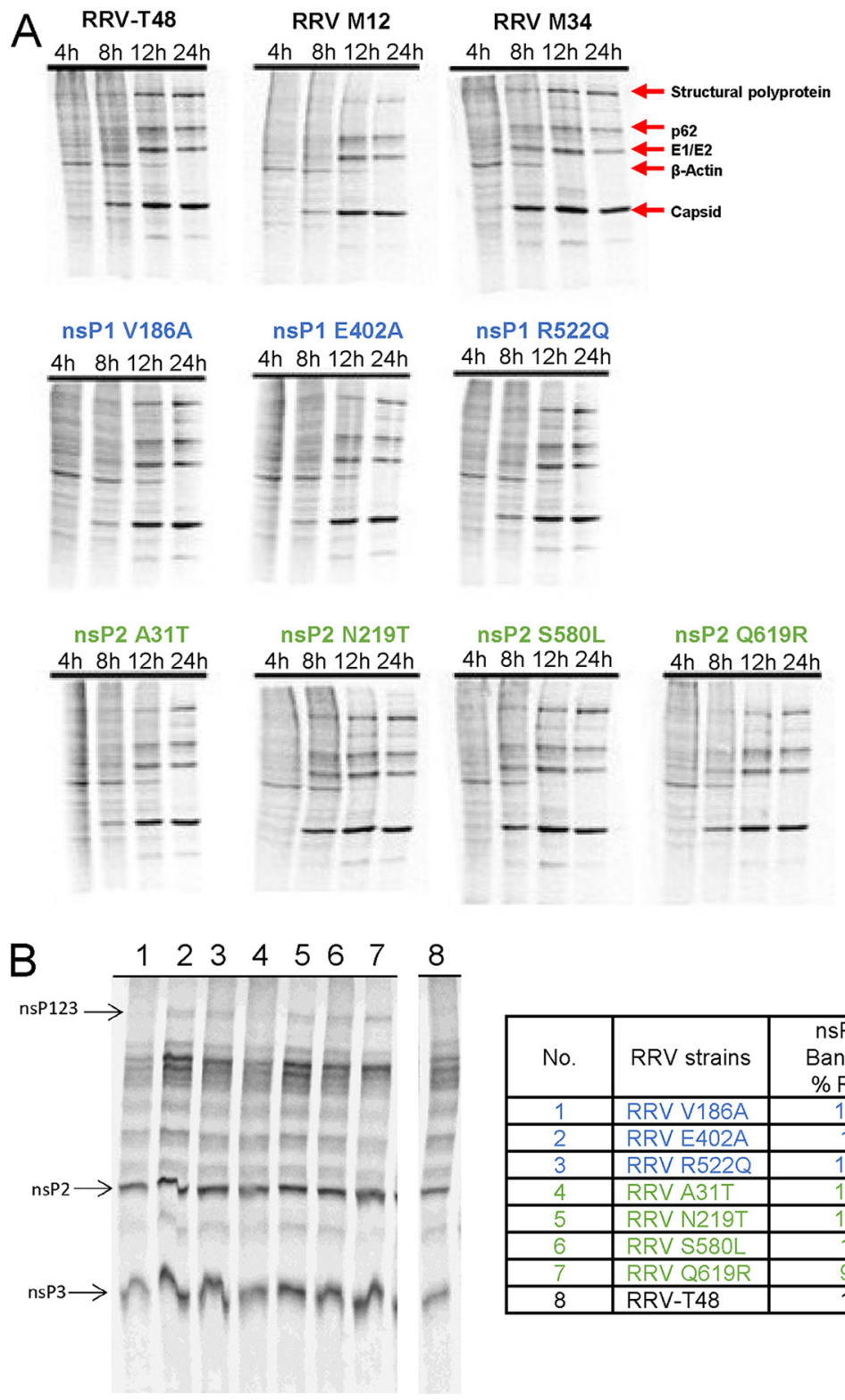

\begin{tabular}{|c|l|c|}
\hline No. & RRV strains & $\begin{array}{c}\text { nsP2/P123 } \\
\text { Band density } \\
\% \text { RRV-T48 }\end{array}$ \\
\hline 1 & RRV V186A & $111 \pm 10$ \\
\hline 2 & RRV E402A & $117 \pm 7$ \\
\hline 3 & RRV R522Q & $101 \pm 10$ \\
\hline 4 & RRV A31T & $109 \pm 10$ \\
\hline 5 & RRV N219T & $115 \pm 10$ \\
\hline 6 & RRV S580L & $112 \pm 7$ \\
\hline 7 & RRV Q619R & $96 \pm 12$ \\
\hline 8 & RRV-T48 & $100 \pm 9$ \\
\hline
\end{tabular}

FIG 9 Analysis of host cell translational shutoff and viral polyprotein processing by recombinant RRV mutants. (A) BHK-21 cells were infected at an MOI of 10 with RRV-T48 and its mutants indicated above the panels. At 4, 6, 12, and $24 \mathrm{~h}$ p.i., cells were labeled with $\left[{ }^{35} \mathrm{~S}\right] \mathrm{Met}$ and $\left.{ }^{35} \mathrm{~S}\right] \mathrm{Cys}$. Cells were collected 30 min later and lysed in $1 \times$ SDS-PAGE loading buffer. Proteins were separated by SDS-PAGE and visualized with a Typhoon imager. The experiment was repeated twice with similar results; data from one experiment are shown. (B) In vitro translations were performed using TnT-SP6 rabbit reticulocyte lysate system and ${ }^{35}$ S]Met. One-tenth of the in vitro translation reaction was separated by SDS-PAGE. nsP2 and P123 bands were quantified by a Typhoon phosphorimager. Three independent experiments were performed in parallel; data from one experiment are shown. nsP2/P123 ratios calculated and normalized to the ratio of RRV-T48 were taken as $100 \%$. The quantified results are presented as the means \pm standard deviations.

Therefore, it is likely that IFN produced in RRV-T48-infected cultures mostly originated from cells that were not infected by the original virus inoculum but were primed by IFN released from infected cells and then were infected by virus progeny, as described for SINV-infected cultures (42). RRV 2548, in contrast, likely induces IFN production in cells infected by the original virus inoculum. If so, this strain has a defect in the suppression of IFN induction. The lack of subsequent increase of IFN levels may be due to limited spread of RRV 2548 in cell culture, consistent with high sensitivity of this strain to the antiviral effects of IFN. 


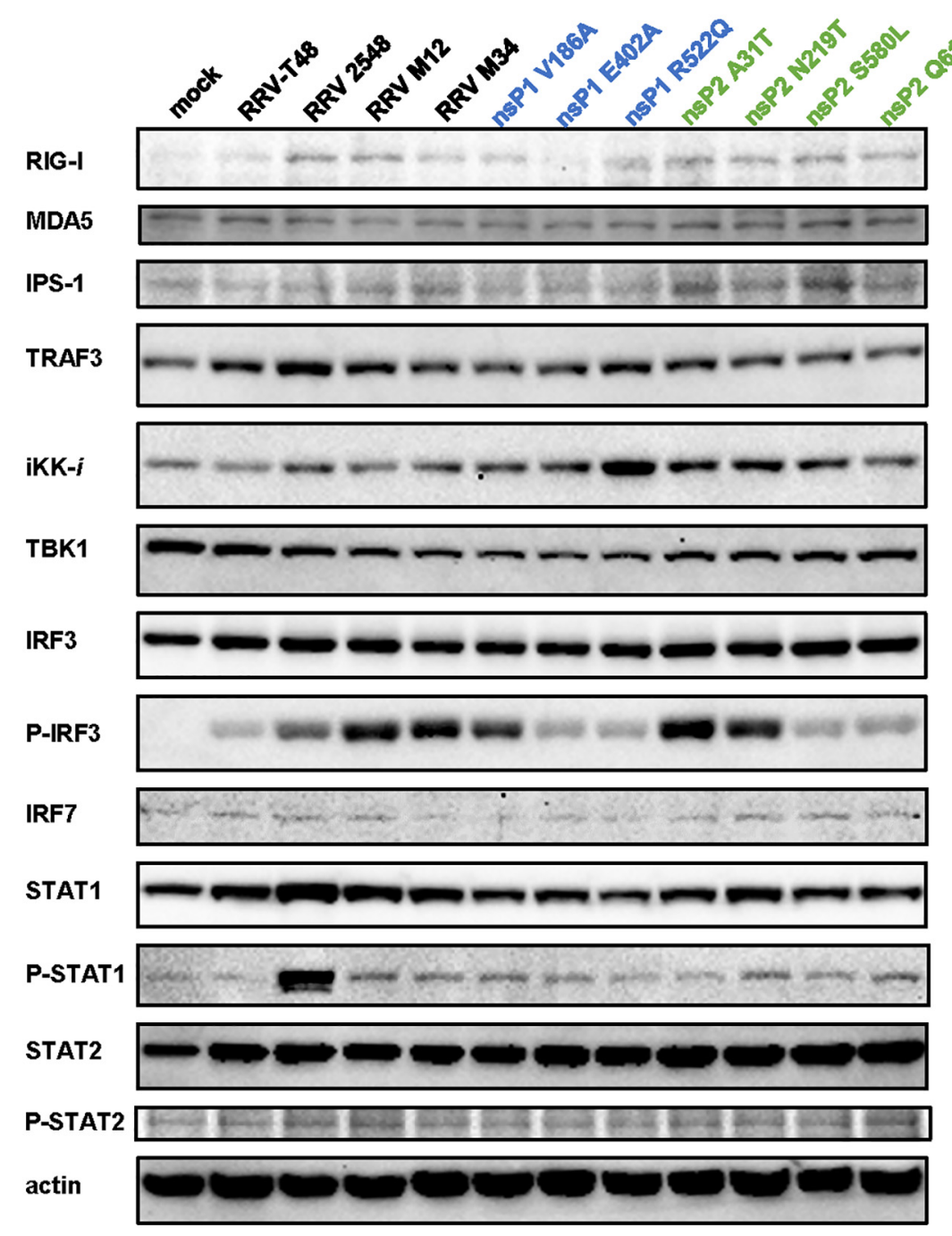

FIG 10 Levels of type I IFN signaling proteins in cells infected with RRV strains, recombinants, and mutants. L929 cells were infected at an MOI of 2 with RRV-T48, RRV 2548, RRV M12, RRV M34, and RRV-T48 harboring the changes indicated above the panels. Cell were collected at $24 \mathrm{~h}$ p.i., lysed, and analyzed by Western blotting using antibodies recognizing RIG-I, MDA5, IPS-1, TRAF3, TBK1, IKK-i, IRF3, p-IRF3, IRF7, STAT1, STAT2, p-STAT1, and p-STAT2. Antibody against $\beta$-actin was used to detect loading control. Blots represent one of two independent reproducible experiments.

Multiple studies using mice deficient in type I IFN have found that alphaviral infection leads to higher mortality rates, more severe disease, and increased viremia compared to that for WT mice (33-35, 43-47). Here, we found that mice with higher levels of type I IFN developed milder inflammatory disease. Therefore, the results of our in vivo study suggest that the type I IFN response in the spleen and serum may be required for protection from RRV disease, particularly at early times postinfection. For CHIKV, SINV, and SFV, nsPs play essential roles in type I IFN modulation $(12,13,26,27)$. Amino acid substitutions have been mapped to nsP1 and nsP2, regions highly involved in type I IFN modulation for Old World alphaviruses. Specifically, one mutation, Ala to Val, either at position 532 or 534 of RRV nsP1 is sufficient to modulate type I IFN induction $(14,23)$. For SINV and SFV, nsP2 is able to inhibit type I IFN by the induction of shutoff host cell gene expression (13). Furthermore, the nsP2 of CHIKV was previously shown to inhibit type I IFN by blocking STAT1 phosphorylation $(15,19)$. All these reports suggest essential roles of nsP1 and nsP2 in type I IFN modulation. It should be noted that involvement of $\mathrm{nsP} 3$ in modulation of the type I IFN response is also possible, given its ability to reverse ATP-ribosylation in infected cells (48) and cause shutoff of host cell 
translation (49). In addition, nsP4 contains determinants responsible for the type I IFN-resistant phenotype of a virulent strain of SFV (50). This study has focused on substitutions found in the nonstructural region of RRV 2548. Interestingly, swapping of the nsP3-nsP4 region of RRV-T48 with that of RRV 2548 indeed increased type I IFN sensitivity, though this effect was less prominent than that caused by swapping of the nsP1-nsP2 region. Thus, our data provide evidence that nsP1-nsP2, and to a lesser extent nsP3-nsP4, are crucial for type I IFN modulation by RRV.

Further investigation of the amino acid differences between nsP1 and nsP2 of RRV-T48 and RRV 2548 associated with type I IFN modulation revealed that all seven substitutions, assumed to be significant due to the nature of swapped amino acid residues and, with one exception, common for different RRV strains (Table 4), had an effect on type I IFN induction and/or sensitivity. When introduced into the genome of RRV-T48, all seven mutations increased the sensitivity to IFN treatment. Altered nsP1 functions could explain the higher type I IFN sensitivities of RRV nsP1 E402A and nsP1 $\mathrm{R} 522 \mathrm{Q}$. nsP1 is part of the viral RNA replicase responsible for the initiation of minusstrand RNA synthesis (51-53). A recent study on RRV nsP1 showed a double mutation of S79C and L224I led to virus attenuation and higher sensitivity to type I IFN in vitro

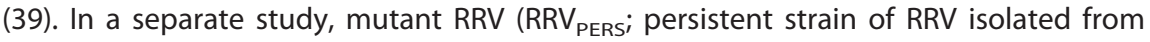
long-term RRV-infected RAW 264.7 cells under ipopolysaccharide [LPS] treatment) was found to have increased resistance to type I IFN in vitro (54). Compared to RRV-T48, $\mathrm{RRV}_{\text {PERS }}$ had 12 amino acid differences, five of which were in the nsP1 region, namely, R143T, A147S, R/G/W154A, R303P, and K499N. These substitutions were suggested to

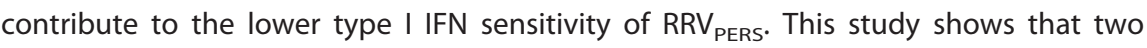
mutations in the C-terminal region of nsP1, E402A and R522Q, are also related to RRV type I IFN sensitivity. These mutations lie outside areas with known effect on protein function. It is possible the mutations may modulate nsP1 function or its interactions with other viral nsPs. Further studies are required to decipher the mechanism by which these mutations alter nsP1 and/or replicase function and how this may modulate RRV type I IFN sensitivity.

RRV nsP2 is a multifunctional enzyme. The C-terminal protease region plays an essential role in replicase precursor (nonstructural polyprotein) processing (51, 55-57). The N-terminal region of nsP2 has RNA helicase and nucleoside triphosphate (NTP) binding domains. Several studies have focused on the role of nsP2 in suppression of IFN induction $(15,19)$. nsP2 was found to inhibit cellular transcription by degrading Rpb1, a key subunit of the RNA polymerase II complex (20). The C-terminal region of CHIKV nsP2 was found to counteract type I IFN by inhibiting JAK-STAT signaling (19). The mutation Q619R identified in our study is located in the C-terminal part of the protease domain of nsP2, which is known to be involved in suppression of the type I IFN response by SFV and CHIKV $(12,19)$. The molecular basis of type I IFN suppression caused by mutations in the corresponding regions of SFV and CHIKV are not well understood, and available data are contradictory $(19,58,59)$. Residue 619 is also close to the recently described V-loop (amino acid residues 674 to 677 in CHIKV nsP2) that is crucial for cytotoxicity and shutoff of cellular transcription (60). Therefore, we speculate that the Q619R substitution may alter cytotoxic properties of nsP2 and/or its nuclear transportation, which were both previously reported to be related to type I IFN modulation (61). In addition, the mutations may affect the ability of nsP2 to counteract induction of type I IFN. Further studies focused on the effect of the mutations on the nsP2 and whole viral replicase are needed to elucidate these mechanisms. For the Q619R substitution, it would also be interesting to analyze whether the elevated IFN induction and increased sensitivity to type I IFN originate from one and the same mechanism or whether the Q619R mutation affects different aspects of interactions between RRV and the host type I IFN system.

On its own, the replicase of SFV induces high levels of type I IFN through the RIG-I/MDA5 pathway, and the effect is enhanced by R649D mutation in the protease part of the protein (62). SINV/G, a SINV variant with a P726G mutation in nsP2, was found to induce much higher levels of type I IFN in vitro than wild-type SINV (13). These 
reports suggest that the processing of replicase precursor is related to type I IFN modulation. We recently reported a similar effect for RRV (23). Therefore, it was tempting to speculate that the S580L and Q619R substitutions in the protease region of RRV nsP2 may both result in altered nsP2 function and lead to perturbed viral RNA synthesis and generation of excess of type I IFN-inducing RNAs. Indeed, all four nsP2 mutants were associated with increased expression of type I IFN regulators RIG-I and/or phosphorylated IRF3. However, none of the positions of the nsP2 mutations match amino acid motifs known to affect activity of nsP2 protease. Indeed, these mutations had no effect on polyprotein processing in the cell-free system; a finding arguing against the above-presented hypothesis. Although STAT1 phosphorylation was dramatically increased in RRV 2548-infected cells compared to that in cells infected with RRV-T48, none of the RRV recombinants or variants harboring point mutations showed a similar level of increased STAT1 phosphorylation as RRV 2548. These results suggest a cumulative effect of the RRV 2548 nonstructural proteins is required to stimulate STAT1 phosphorylation. The effect of RRV infection on STAT2 phosphorylation was generally small, and the differences between parental viruses were minimal. RRV-T48 harboring the nsP2 Q619R substitution stimulated STAT2 phosphorylation to a similar level as RRV 2548, again indicating that the mutation at position 619 may affect the ability of nsP2 to counteract induction of type I IFN.

From a preliminary sequence variability analysis (Table 4), we found that six of the seven significant substitutions found in the nsP1-nsP2 region of RRV 2548 exist among 26 of the 30 RRV stains. In 14 of the 30 RRV isolates, nsP1 186A, nsP1 522Q, nsP2 219T, and nsP2 580L have been found somehow linked together. nsP1 31T and nsP2 619R were found to occur alone in seven and three isolates, respectively, suggesting these two mutations may result from independent selection pressure. Taken together, these six substitutions and their combinations occur commonly under natural conditions. Interestingly, only residues found either in RRV-T48 or RRV 2548 were also found in other RRV strains, indicating that for each of these positions, only two amino acid residues have been naturally selected, highlighting the functional importance of these positions and corresponding amino acids. Only nsP 402A exclusively exists in RRV 2548 and may therefore contribute to its distinguished sensitivity/induction to type I IFN.

In conclusion, we have characterized the genetic, phenotypic, and pathological properties of the RRV field strain, RRV 2548, both in vitro and in vivo. Through genomic analysis, we have identified RRV nsP determinants related to type I IFN modulation. This study suggests the mechanism of RRV type I IFN modulation involves amino acid determinants in nsP1 and nsP2 and provides new insights into alphavirus-host interactions and viral pathogenesis.

\section{MATERIALS AND METHODS}

Ethics statement. All animal experiments were approved by the Animal Ethics Committee of Griffith University (Gly/01/14/AEC). All procedures conformed to the National Health and Medical Research Council guidelines (63). The humane endpoint was defined as a clinical disease score of 7 (moribund) or weight loss greater than $15 \%$.

Cells and viruses. Vero cells (88020401; Sigma-Aldrich) were propagated in Opti-MEM (Life Technologies) supplemented with $5 \%$ fetal bovine serum (FBS; Bovogen). HeLa (ATCC CCL-2) and mouse fibroblast $\mathrm{L} 929$ cells (ATCC CCL-1) were cultivated using Dulbecco's modified Eagle's medium (DMEM) supplemented with 5\% FBS. HeLa cells were kindly provided by Nigel McMillan (Griffith University, School of Medical Science), while L929 cells were a gift from Andreas Suhrbier (QIMR Berghofer Medical Research Institute). BHK-21 cells (ATTC CCL-10) were grown in Glasgow minimum essential medium (GMEM) supplemented with $10 \%$ FBS, $2 \%$ tryptose phosphate broth, $10 \mathrm{mM} \mathrm{HEPES}, 100 \mu \mathrm{g} / \mathrm{ml}$ streptomycin, and $100 \mathrm{IU} / \mathrm{ml}$ penicillin. All cells were maintained at $37^{\circ} \mathrm{C}$ and $5 \% \mathrm{CO}_{2}$.

The prototype infectious clone of RRV-T48 (kindly provided by Richard Kuhn, Purdue University) is based on virus originally isolated from Aedes vigilax in northeast Queensland that was passaged 10 times in suckling mice and twice in Vero cells prior to generating an infectious clone $(64,65)$. The RRV-T48 virus stock was generated by in vitro transcription of infection clone DNA using an mMESSAGE mMACHINE SP6 Transcription kit (Ambion) followed by virus rescue as previously described (64). Briefly, $2 \mu \mathrm{g}$ of RRV-T48 cDNA plasmids were linearized and transcribed, with the resulting transcription products electroporated into Vero cells using an electroporator (Eppendorf, Germany). Recovered viruses were amplified on Vero cells. The RRV field strains (Fig. 1) were amplified on Vero cells for 3 passages. 
Virus titers were determined by standard plaque assay on Vero cells (66). Briefly, Vero cell monolayers were infected with serial dilutions of viral stocks prior to the addition of a $0.2 \%$ agarose overlay. Plates were incubated for $48 \mathrm{~h}$, after which the cells were fixed with $4 \%$ formaldehyde and stained with $0.05 \%$ crystal violet. Viral titers were calculated using the following formula: $\mathrm{PFU} / \mathrm{ml}=$ [average plaques/volume $(\mathrm{ml})$ of virus added] $\times$ dilution factor (67). Virus stocks were stored in $0.5-\mathrm{ml}$ aliquots at $-80^{\circ} \mathrm{C}$.

Genome sequencing. Genomic RNA of RRV 2548 was extracted by using TRIzol RNA isolation reagents (Life Technologies) according to the manufacturer's instructions. The first strand of CDNA was synthesized using a SuperScript III first-strand synthesis system (Invitrogen) with oligo(dT) as a primer. The cDNA corresponding to the nonstructural region of the RRV 2548 genome was amplified by PCR using the CDNA as the template and then sequenced by DNA Sanger sequencing (AGRF); the sequence of this region was assembled by Vector NTI software.

Chimeric viruses. The CDNA fragments F12 and F34, containing the sequences corresponding to RRV 2548 nsP1-nsP2 or nsP3-nsP4 regions, respectively, were both amplified by PCR with the RRV 2548 cDNA as a template. The primers used for amplification of these two fragments were F12-forward (TTAACGC CCGAAGGAGGTTG), F12-reverse (GGCCCCTAGGTCAAGATCATAAATAC), F34-forward (TTGACCTAGGATTA CCCCTGAATGC) and F34-reverse (TITAGGGCCCTTAAGCCTAGTAAC). F12 and F34 were then cloned into RRV-T48 infectious clone backbone, replacing their counterpart fragments and making the chimeric RRV M12 and RRV M34 infectious clones, respectively. RRV M12 and RRV M34 were rescued and propagated as described for RRV-T48.

Site-directed mutagenesis. Seven point mutations, each substituting a single amino acid residue in RRV-T48 nsP1 or nsP2 (nsP1 V186A, nsP1 E402A, nsP1 R522Q, nsP2 A31T, nsP2 N219T, nsP2 S580L, and nsP2 Q619R), were introduced into RRV-T48 subclone designated pUC19-F7 using QuikChange II XL site-directed mutagenesis kit (Agilent) according to the manufacturer's instructions. Fragments harboring the correct mutation were cloned back to the RRV-T48 infectious clone backbone, replacing the original fragments. The new RRV-T48 infectious clones containing point mutations were used to generate seven RRV mutants as described above.

Pulse labeling of proteins in infected cells. BHK-21 cells were seeded on 35-mm plates and infected separately with RRV-T48 and nine RRV mutants generated in this study at an MOI of 10. At 4, 8, 12 , and $24 \mathrm{~h}$ postinfection, cells were starved in methionine- and cysteine-free DMEM for $30 \mathrm{~min}$ and labeled for $30 \mathrm{~min}$ with $0.5 \mathrm{ml}$ starvation medium containing $50 \mu \mathrm{Ci}\left[{ }^{35} \mathrm{~S}\right] \mathrm{Met}$ and [ $\left.{ }^{35} \mathrm{~S}\right] \mathrm{Cys}(1,175 \mathrm{Ci} /$ mmol; Perkin Elmer, USA). After labeling, cells were rinsed with PBS, lysed with $0.1 \mathrm{ml}$ of $1 \times$ SDS loading buffer, and boiled for $5 \mathrm{~min}$. Obtained samples were analyzed by 10\% SDS-PAGE; labeled proteins were visualized with a Typhoon imager.

IFN- $\boldsymbol{\beta}$ treatment of cells. Vero cells were seeded into 12-well plates and cultured overnight. The cell growth medium was discarded, and cell monolayers were washed once with PBS. Serum-free medium containing $0.0,0.05,0.1$, or $0.25 \mathrm{ng} / \mathrm{ml}$ human IFN- $\beta$ (PeproTech) was added to the cells, and the plates were incubated at $37^{\circ} \mathrm{C}$ for $24 \mathrm{~h}$ before virus infection.

SDS-PAGE and Western blot analysis. L929 cells were lysed in RIPA buffer $(150 \mathrm{mM} \mathrm{NaCl}, 0.1 \%$ Triton $\mathrm{X}-100,0.5 \%$ sodium deoxycholate, $0.1 \% \mathrm{SDS}, 50 \mathrm{mM}$ Tris- $\mathrm{HCl}$ [pH 8.0], $1 \%$ protease inhibitor cocktail; Sigma) and diluted 1:2 with $2 \times$ protein solubilizing buffer $(50 \mathrm{mM}$ Tris-HCl [pH 6.8], 2\% [wt/vol] $\mathrm{SDS}, 20 \%$ [vol/vol] glycerol, $50 \mu \mathrm{g} / \mathrm{ml}$ bromophenol blue, $10 \mathrm{mM}$ dithiothreitol [DTT]) and heated at $99^{\circ} \mathrm{C}$ for $5 \mathrm{~min}$. Proteins were separated by SDS-PAGE followed by transfer onto a polyvinylidene difluoride (PVDF) membrane (Millipore). Membranes were probed by the following antibodies from Santa Cruz Biotechnology Inc.: RIG-I (H-300, catalog number [cat no.] sc-98911); MDA5 (H-61, cat no. sc-134513); IPS-1 (E-3, cat no. sc-166583); TRAF3 (H-122, cat no. sc-1828); TBK1 (108A429, cat no. sc-52957); IKK-i (A11, cat no. sc-376114); IRF3 (SL-12, cat no. sc-33641); IRF7 (H-246, cat no. sc-9083); STAT1 (c136, cat no. sc-464); STAT2 (B3, cat no. C-514193), and $\beta$-actin (C4, cat no. sc-47778). Antibody against phosphorylated IRFS (p-IRF3) (4D4G, cat no. 4947) was purchased from Cell Signaling Technology. Antibody against p-STAT1 (Y701, cat no. ab29045) was purchased from Abcam. Antibody against p-STAT2 (Y690, cat no. SAB4503836) was purchased from Sigma-Aldrich. Proteins were visualized with enhanced chemiluminescence (Amersham ECL Select Western blotting detection reagent) according to the manufacturer's instructions, using either anti-rabbit lgG horseradish peroxidase (HRP)-linked antibody (cat no. 7074; Cell Signaling Technology), or anti-mouse IgG HRP-linked antibody (cat no. 7076; Cell Signaling Technology).

Transfection with poly(I.C). Transfections were performed with Lipofectamine 2000 reagent (Life Technologies) according to the manufacturer's protocol when cells reached $80 \%$ confluence. Briefly, $10 \mu \mathrm{g}$ of poly(I.C) (Sigma) was added to $50 \mu \mathrm{l}$ serum-free culture medium, mixed with $3 \mu \mathrm{l}$ Lipofectamine 2000 (Life Technologies), and diluted in $50 \mu \mathrm{l}$ serum-free culture medium. The transfection mixture was incubated for $20 \mathrm{~min}$ at room temperature. Then, the supernatants were removed from the cells and replaced with serum-free medium. The transfection mixture was added dropwise, and plates were incubated at $37^{\circ} \mathrm{C}$ for $6 \mathrm{~h}$, after which, the culture medium was replaced with complete growth medium (Opti-MEM with $5 \% \mathrm{FBS}$ ). The cells were incubated at $37^{\circ} \mathrm{C}$ for a further 18 to $24 \mathrm{~h}$.

Mouse infections and disease monitoring. C57BL/6 WT mice were obtained from the Animal Resources Centre (Perth, Australia). Twenty-day-old C57BL/6 WT mice were inoculated subcutaneously in the thorax below the right forelimb with $10^{4}$ PFU RRV diluted in PBS to a volume of $50 \mu \mathrm{l}$ (68). Mock-infected control mice were inoculated with PBS only. Mice were weighed and scored for disease daily. RRV disease scores were assessed based on strength and hindlimb dysfunction using the following scale: 0 , no disease signs; 1 , ruffled fur; 2 , very mild hindlimb weakness; 3 , mild hindlimb weakness; 4 , moderate hindlimb weakness and dragging of hindlimbs; 5 , severe hindlimb weakness/dragging; 6 , complete loss of hindlimb function; 7 , moribund. Humane endpoint was defined as clinical disease score of 7 or weight loss greater than $15 \%$ of starting weight (69). 
Type I IFN detection bioassay. The concentration of type I IFN in cell culture supernatants or mouse tissues was assessed by a CPE inhibition bioassay using SFV infection of L929 cells (70). Briefly, L929 cells were seeded into 96 -well flat-bottom plates at $2.5 \times 10^{4}$ cells/well. Samples were serially diluted (1:2 dilutions) in serum-free DMEM medium and UV inactivated for $1 \mathrm{~h}$. Samples were then added to the L929 cells and cultured for $24 \mathrm{~h} ; 2.5 \times 10^{3}$ PFU of SFV was added to each well. Forty-eight hours later, cells were fixed with $4 \%$ formaldehyde, stained with $0.05 \%$ crystal violet for $10 \mathrm{~min}$, and washed once with PBS. The crystal violet was released from stained cells by adding $100 \mu \mathrm{l}$ of $100 \%$ methanol to each well. The absorbance of crystal violet dissolved in methanol was measured at a wavelength of $595 \mathrm{~nm}$. The type I IFN concentrations in units per milliliter were calculated according to the protection against SFV infection provided by treatment with known concentrations of human IFN- $\beta$ (Sigma-Aldrich). The sensitivity of the assay ( $50 \%$ protection against SFV infection at an $\mathrm{MOI}$ of 0.1$)$ was 10 international units (IU) per ml.

Histological analysis. Mouse quadriceps were collected and fixed in $4 \%$ paraformaldehyde (PFA), followed by paraffin embedding. Samples were cut into 5 - $\mu$ m-thick sections and stained with hematoxylin and eosin (H\&E). Images were taken using a Nikon Eclipse TS100 inverted microscope, and the density of the infiltrated cells was analyzed using ImageJ software.

Polyprotein processing analysis. In vitro translation was carried out using a TnT-SP6-coupled rabbit reticulocyte system (Promega) according to the manufacturer's protocol. Ten-microliter reaction mixtures contained $4 \mu \mathrm{Ci}\left[{ }^{35} \mathrm{~S}\right] \mathrm{Met}$ (EasyTag Express protein labeling mix; PerkinElmer) and $500 \mathrm{ng}$ infectious clone DNA of RRV V186A, RRV E402A, RRV R522Q, RRV A31T, RRV N219T, RRV S580L, RRV Q619R, and RRV-T48. The reaction mixtures were incubated for $45 \mathrm{~min}$ at $30^{\circ} \mathrm{C}$, stopped with $1 \mathrm{mM}$ cycloheximide for $5 \mathrm{~min}$, treated with $10 \mathrm{ng}$ of RNase A for another $5 \mathrm{~min}$, and denatured with equal volumes of SDS loading buffer at $70^{\circ} \mathrm{C}$ for $10 \mathrm{~min}$. One-tenth of the reaction volume was separated by $8 \%$ SDS-PAGE; the gels were vacuum dried and visualized with a Typhoon phosphorimager (GE Healthcare). Intensities of nsP2 and P123 precursor bands were quantified using ImageQuant TL software (GE Healthcare). The ratio between intensities of nsP2 and unprocessed $\mathrm{P} 123$ represents the efficiency of polyprotein processing. nsP2/P123 ratio of RRV-T48 was taken as 100\%.

Sequence variability analysis. Thirty RRV genome sequences containing the full nonstructural region were selected randomly from GenBank. The sequences were analyzed with Bioedit software. nsP1 and nsP2 sequences were aligned and compared with those of RRV-T48 and 2548 strains.

Statistical analysis. Data for mouse weight, IFN bioassay, and plaque assays were analyzed using two-way analysis of variance (ANOVA) with Bonferroni's post hoc test. All data were tested for normality using the D'Agostino-Pearson normality test prior to analysis. RRV type I IFN sensitivity, infiltrated cell density assay, and differences in mouse clinical scores were analyzed using the nonparametric MannWhitney test. All statistical analyses were performed with GraphPad Prism software.

\section{ACKNOWLEDGMENTS}

We thank Joseph Freitas for excellent technical assistance.

This project was supported by an Australian National Health and Medical Research Council grant to S.M. (APP1031024), an Australian Research Council grant to S.M. (LP0990827), and an Estonian Research Council grant to A.M. (IUT20-27). The funders had no role in study design, data collection and interpretation, or the decision to submit the work for publication. A.T. is the recipient of a National Health and Medical Research Council Early Career Research Fellowship (identifier [ID] 1073108) and grant (ID 1122897). S.M. is the recipient of an NHMRC Senior Research Fellowship (ID 1154347).

\section{REFERENCES}

1. Barber B, Denholm JT, Spelman D. 2009. Ross River virus. Aust Fam Physician 38:586-589.

2. Aubry M, Kama M, Vanhomwegen J, Teissier A, Mariteragi-Helle T, Hue S, Hibberd ML, Manuguerra JC, Christi K, Watson CH, Nilles EJ, Lau CL, Aaskov J, Musso D, Kucharski AJ, Cao-Lormeau VM. 2019. Ross River virus antibody prevalence, Fiji Islands, 2013-2015. Emerg Infect Dis 25: 827-830. https://doi.org/10.3201/eid2504.180694.

3. Russell RC. 2002. Ross River virus: ecology and distribution. Annu Rev Entomol 47:1-31. https://doi.org/10.1146/annurev.ento.47.091201.145100.

4. Aaskov J. 2015. Explainer: what is Ross River virus and how is it treated? http://theconversation.com/explainer-what-is-ross-river-virus-and-how -is-it-treated-37889. Accessed

5. Australia's National Notifiable Diseases Surveillance System. 2015. Number of notifications of Ross River virus infection, Australia, in the period of 1991 to 2014 and year-to-date notifications for 2015, October ed. Australia's National Notifiable Diseases Surveillance System (NNDSS), Canberra, Australia.

6. Harley D, Sleigh A, Ritchie S. 2001. Ross River virus transmission, infec- tion, and disease: a cross-disciplinary review. Clin Microbiol Rev 14: 909-932. https://doi.org/10.1128/CMR.14.4.909-932.2001.

7. Gonzalez-Navajas JM, Lee J, David M, Raz E. 2012. Immunomodulatory functions of type I interferons. Nat Rev Immunol 12:125-135. https://doi .org/10.1038/nri3133.

8. Seo YJ, Hahm B. 2010. Type I interferon modulates the battle of host immune system against viruses. Adv Appl Microbiol 73:83-101. https:// doi.org/10.1016/S0065-2164(10)73004-5.

9. Onomoto K, Onoguchi K, Takahasi K, Fujita T. 2010. Type I interferon production induced by RIG-I-like receptors. J Interferon Cytokine Res 30:875-881. https://doi.org/10.1089/jir.2010.0117.

10. Basler CF, Garcia-Sastre A. 2002. Viruses and the type I interferon antiviral system: induction and evasion. Int Rev Immunol 21:305-337. https://doi.org/10.1080/08830180213277.

11. Aguilar PV, Weaver SC, Basler CF. 2007. Capsid protein of eastern equine encephalitis virus inhibits host cell gene expression. J Virol 81: 3866-3876. https://doi.org/10.1128/JVI.02075-06.

12. Breakwell L, Dosenovic $P$, Karlsson Hedestam GB, D'Amato M, Liljeström P, Fazakerley J, Mclnerney GM. 2007. Semliki Forest virus nonstructural 
protein 2 is involved in suppression of the type I interferon response. J Virol 81:8677-8684. https://doi.org/10.1128/JVI.02411-06.

13. Frolova El, Fayzulin RZ, Cook SH, Griffin DE, Rice CM, Frolov I. 2002. Roles of nonstructural protein nsP2 and alpha/beta interferons in determining the outcome of Sindbis virus infection. J Virol 76:11254-11264. https:// doi.org/10.1128/jvi.76.22.11254-11264.2002.

14. Cruz CC, Suthar MS, Montgomery SA, Shabman R, Simmons J, Johnston RE, Morrison TE, Heise MT. 2010. Modulation of type I IFN induction by a virulence determinant within the alphavirus nsP1 protein. Virology 399:1-10. https://doi.org/10.1016/j.virol.2009.12.031.

15. Fros JJ, Liu WJ, Prow NA, Geertsema $C$, Ligtenberg $M$, Vanlandingham DL, Schnettler E, Vlak JM, Suhrbier A, Khromykh AA, Pijlman GP. 2010. Chikungunya virus nonstructural protein 2 inhibits type $\mathrm{I} / \mathrm{II}$ interferonstimulated JAK-STAT signaling. J Virol 84:10877-10887. https://doi.org/ 10.1128/JVI.00949-10.

16. Simmons JD, White LJ, Morrison TE, Montgomery SA, Whitmore AC, Johnston RE, Heise MT. 2009. Venezuelan equine encephalitis virus disrupts STAT1 signaling by distinct mechanisms independent of host shutoff. J Virol 83:10571-10581. https://doi.org/10.1128/JVI.01041-09.

17. Simmons JD, Wollish AC, Heise MT. 2010. A determinant of Sindbis virus neurovirulence enables efficient disruption of Jak/STAT signaling. J Virol 84:11429-11439. https://doi.org/10.1128/JVI.00577-10.

18. Goertz GP, McNally KL, Robertson SJ, Best SM, Pijlman GP, Fros JJ. 2018. The Methyltransferase-like domain of chikungunya virus nsP2 inhibits the interferon response by promoting the nuclear export of STAT1. J Virol 92:e01008-18. https://doi.org/10.1128/JVI.01008-18.

19. Fros JJ, van der Maten E, Vlak JM, Pijlman GP. 2013. The C-terminal domain of chikungunya virus nsP2 independently governs viral RNA replication, cytopathicity, and inhibition of interferon signaling. J Virol 87:10394-10400. https://doi.org/10.1128/JVI.00884-13.

20. Akhrymuk I, Kulemzin SV, Frolova El. 2012. Evasion of the innate immune response: the Old World alphavirus nsP2 protein induces rapid degradation of Rpb1, a catalytic subunit of RNA polymerase II. J Virol 86: 7180-7191. https://doi.org/10.1128/JVI.00541-12.

21. Rikkonen M, Peranen J, Kaariainen L. 1994. Nuclear targeting of Semliki Forest virus nsP2. Arch Virol Suppl 9:369-377. https://doi.org/10.1007/ 978-3-7091-9326-6_37.

22. Her Z, Teng TS, Tan JJ, Teo TH, Kam YW, Lum FM, Lee WW, Gabriel C, Melchiotti R, Andiappan AK, Lulla V, Lulla A, Win MK, Chow A, Biswas SK, Leo YS, Lecuit M, Merits A, Renia L, Ng LF. 2015. Loss of TLR3 aggravates $\mathrm{CHIKV}$ replication and pathology due to an altered virus-specific neutralizing antibody response. EMBO Mol Med 7:24-41. https://doi.org/10 .15252/emmm.201404459.

23. Liu X, Mutso M, Utt A, Lepland A, Herrero LJ, Taylor A, Bettadapura J, Rudd PA, Merits A, Mahalingam S. 2018. Decreased virulence of Ross River virus harboring a mutation in the first cleavage site of nonstructural polyprotein is caused by a novel mechanism leading to increased production of interferon-inducing RNAs. mBio 9:e00044-18. https://doi .org/10.1128/mBio.00044-18.

24. Sammels LM, Coelen RJ, Lindsay MD, Mackenzie JS. 1995. Geographic distribution and evolution of Ross River virus in Australia and the Pacific Islands. Virology 212:20-29. https://doi.org/10.1006/viro.1995.1449.

25. Lindsay MD, Coelen RJ, Mackenzie JS. 1993. Genetic heterogeneity among isolates of Ross River virus from different geographical regions. J Virol 67:3576-3585. https://doi.org/10.1128/JVI.67.6.3576-3585.1993.

26. Bordi L, Meschi S, Selleri M, Lalle E, Castilletti C, Carletti F, Chiappini R, Di Caro A, Capobianchi MR. 2011. Chikungunya virus isolates with/without A226V mutation show different sensitivity to IFN-a, but similar replication kinetics in nonhuman primate cells. New Microbiol 34:87-91.

27. Tuittila M, Hinkkanen AE. 2003. Amino acid mutations in the replicase protein nsP3 of Semliki Forest virus cumulatively affect neurovirulence. J Gen Virol 84:1525-1533. https://doi.org/10.1099/vir.0.18936-0.

28. Nagai Y, Ito Y, Hamaguchi M, Yoshida T, Matsumoto T. 1981. Relation of interferon production to the limited replication of Newcastle disease virus in L cells. J Gen Virol 55:109-116. https://doi.org/10.1099/0022 -1317-55-1-109.

29. MacDonald MR, Machlin ES, Albin OR, Levy DE. 2007. The zinc finger antiviral protein acts synergistically with an interferon-induced factor for maximal activity against alphaviruses. J Virol 81:13509-13518. https:// doi.org/10.1128/JVI.00402-07.

30. Antalis TM, La Linn M, Donnan K, Mateo L, Gardner J, Dickinson JL, Buttigieg K, Suhrbier A. 1998. The serine proteinase inhibitor (serpin) plasminogen activation inhibitor type 2 protects against viral cytopathic effects by constitutive interferon alpha/beta priming. J Exp Med 187: 1799-1811. https://doi.org/10.1084/jem.187.11.1799.

31. Schilte C, Couderc T, Chretien F, Sourisseau M, Gangneux N, GuivelBenhassine F, Kraxner A, Tschopp J, Higgs S, Michault A, ArenzanaSeisdedos F, Colonna M, Peduto L, Schwartz O, Lecuit M, Albert ML. 2010. Type I IFN controls chikungunya virus via its action on nonhematopoietic cells. J Exp Med 207:429-442. https://doi.org/10.1084/jem .20090851.

32. Zhang Y, Burke CW, Ryman KD, Klimstra WB. 2007. Identification and characterization of interferon-induced proteins that inhibit alphavirus replication. J Virol 81:11246-11255. https://doi.org/10.1128/JVI .01282-07.

33. Grieder FB, Vogel SN. 1999. Role of interferon and interferon regulatory factors in early protection against Venezuelan equine encephalitis virus infection. Virology 257:106-118. https://doi.org/10.1006/viro.1999.9662.

34. Rudd PA, Wilson J, Gardner J, Larcher T, Babarit C, Le T, Anraku I, Kumagai Y, Loo YM, Gale M, Jr, Akira S, Khromykh AA, Suhrbier A. 2012. Interferon response factors 3 and 7 protect against chikungunya virus hemorrhagic fever and shock. J Virol 86:9888-9898. https://doi.org/10 .1128/JVI.00956-12.

35. Ryman KD, Klimstra WB, Nguyen KB, Biron CA, Johnston RE. 2000. Alpha beta interferon protects adult mice from fatal sindbis virus infection and is an important determinant of cell and tissue tropism. J Virol 74: 3366-3378. https://doi.org/10.1128/jvi.74.7.3366-3378.2000.

36. Shabman RS, Morrison TE, Moore C, White L, Suthar MS, Hueston L, Rulli N, Lidbury B, Ting JP, Mahalingam S, Heise MT. 2007. Differential induction of type I interferon responses in myeloid dendritic cells by mosquito and mammalian-cell-derived alphaviruses. J Virol 81:237-247. https://doi .org/10.1128/JVI.01590-06.

37. Bernard KA, Klimstra WB, Johnston RE. 2000. Mutations in the E2 glycoprotein of Venezuelan equine encephalitis virus confer heparan sulfate interaction, low morbidity, and rapid clearance from blood of mice. Virology 276:93-103. https://doi.org/10.1006/viro.2000.0546.

38. Hyde JL, Gardner CL, Kimura T, White JP, Liu G, Trobaugh DW, Huang C, Tonelli M, Paessler S, Takeda K, Klimstra WB, Amarasinghe GK, Diamond MS. 2014. A viral RNA structural element alters host recognition of nonself RNA. Science 343:783-787. https://doi.org/10.1126/ science. 1248465 .

39. Stoermer Burrack KA, Hawman DW, Jupille HJ, Oko L, Minor M, Shives KD, Gunn BM, Long KM, Morrison TE. 2014. Attenuating mutations in nsP1 reveal tissue-specific mechanisms for control of Ross River virus infection. J Virol 88:3719-3732. https://doi.org/10.1128/JVI.02609-13.

40. Lam V, Duca KA, Yin J. 2005. Arrested spread of vesicular stomatitis virus infections in vitro depends on interferon-mediated antiviral activity. Biotechnol Bioeng 90:793-804. https://doi.org/10.1002/bit.20467.

41. Otsuki K, Maeda J, Yamamoto H, Tsubokura M. 1979. Studies on avian infectious bronchitis virus (IBV). III. Interferon induction by and sensitivity to interferon of IBV. Arch Virol 60:249-255. https://doi.org/10.1007/ bf01317496.

42. Frolov I, Akhrymuk M, Akhrymuk I, Atasheva S, Frolova El. 2012. Early events in alphavirus replication determine the outcome of infection. J Virol 86:5055-5066. https://doi.org/10.1128/JVI.07223-11.

43. Hwang SY, Hertzog PJ, Holland KA, Sumarsono SH, Tymms MJ, Hamilton JA, Whitty G, Bertoncello I, Kola I. 1995. A null mutation in the gene encoding a type I interferon receptor component eliminates antiproliferative and antiviral responses to interferons alpha and beta and alters macrophage responses. Proc Natl Acad Sci U S A 92:11284-11288. https://doi.org/10.1073/pnas.92.24.11284.

44. Muller U, Steinhoff U, Reis LF, Hemmi S, Pavlovic J, Zinkernagel RM, Aguet M. 1994. Functional role of type I and type II interferons in antiviral defense. Science 264:1918-1921. https://doi.org/10.1126/ science. 8009221 .

45. Couderc T, Chretien F, Schilte C, Disson O, Brigitte M, Guivel-Benhassine F, Touret Y, Barau G, Cayet N, Schuffenecker I, Despres P, ArenzanaSeisdedos F, Michault A, Albert ML, Lecuit M. 2008. A mouse model for chikungunya: young age and inefficient type-I interferon signaling are risk factors for severe disease. PLoS Pathog 4:e29. https://doi.org/10 .1371/journal.ppat.0040029.

46. Ryman KD, Meier KC, Gardner CL, Adegboyega PA, Klimstra WB. 2007. Non-pathogenic Sindbis virus causes hemorrhagic fever in the absence of alpha/beta and gamma interferons. Virology 368:273-285. https://doi .org/10.1016/j.virol.2007.06.039.

47. White LJ, Wang JG, Davis NL, Johnston RE. 2001. Role of alpha/beta interferon in Venezuelan equine encephalitis virus pathogenesis: effect 
of an attenuating mutation in the $5^{\prime}$ untranslated region. $J$ Virol 75 : 3706-3718. https://doi.org/10.1128/JVI.75.8.3706-3718.2001.

48. Li C, Debing Y, Jankevicius G, Neyts J, Ahel I, Coutard B, Canard B. 2016 Viral macro domains reverse protein ADP-ribosylation. J Virol 90: 8478-8486. https://doi.org/10.1128/JVI.00705-16.

49. Akhrymuk I, Frolov I, Frolova El. 2018. Sindbis virus infection causes cell death by nsP2-induced transcriptional shutoff or by nsP3-dependent translational shutoff. J Virol 92:e01388-18. https://doi.org/10.1128/JVI .01388-18.

50. Martikainen $M$, Niittykoski $M$, von und zu Fraunberg $M$, Immonen $A$, Koponen S, van Geenen M, Vähä-Koskela M, Ylösmäki E, Jääskeläinen JE, Saksela K, Hinkkanen A. 2015. MicroRNA-attenuated clone of virulent Semliki Forest virus overcomes antiviral type I interferon in resistant mouse CT-2A Glioma. J Virol 89:10637-10647. https://doi.org/10.1128/ JVI.01868-15.

51. Hahn YS, Grakoui A, Rice CM, Strauss EG, Strauss JH. 1989. Mapping of RNA- temperature-sensitive mutants of Sindbis virus: complementation group F mutants have lesions in nsP4. J Virol 63:1194-1202. https://doi .org/10.1128/JVI.63.3.1194-1202.1989.

52. Sawicki DL, Sawicki SG, Keranen S, Kaariainen L. 1981. Specific Sindbis virus-coded function for minus-strand RNA synthesis. J Virol 39:348-358. https://doi.org/10.1128/JVI.39.2.348-358.1981.

53. Wang YF, Sawicki SG, Sawicki DL. 1991. Sindbis virus nsP1 functions in negative-strand RNA synthesis. J Virol 65:985-988. https://doi.org/10 1128/JVI.65.2.985-988.1991.

54. Lidbury BA, Rulli NE, Musso CM, Cossetto SB, Zaid A, Suhrbier A, Rothenfluh HS, Rolph MS, Mahalingam S. 2011. Identification and characterization of a ross river virus variant that grows persistently in macrophages, shows altered disease kinetics in a mouse model, and exhibits resistance to type I interferon. J Virol 85:5651-5663. https://doi.org/10.1128/JVI .01189-10.

55. Sawicki DL, Sawicki SG. 1985. Functional analysis of the A complementation group mutants of Sindbis HR virus. Virology 144:20-34. https:// doi.org/10.1016/0042-6822(85)90301-0.

56. Sawicki DL, Sawicki SG. 1993. A second nonstructural protein functions in the regulation of alphavirus negative-strand RNA synthesis. J Virol 67:3605-3610. https://doi.org/10.1128/JVI.67.6.3605-3610.1993.

57. De I, Sawicki SG, Sawicki DL. 1996. Sindbis virus RNA-negative mutants that fail to convert from minus-strand to plus-strand synthesis: role of the nsP2 protein. J Virol 70:2706-2719. https://doi.org/10.1128/JVI.70.5 .2706-2719.1996.

58. Utt A, Das PK, Varjak M, Lulla V, Lulla A, Merits A. 2015. Mutations conferring a noncytotoxic phenotype on chikungunya virus replicons compromise enzymatic properties of nonstructural protein 2. J Virol 89:3145-3162. https://doi.org/10.1128/JVI.03213-14.

59. Tamm K, Merits A, Sarand I. 2008. Mutations in the nuclear localization signal of nsP2 influencing RNA synthesis, protein expression and cyto- toxicity of Semliki Forest virus. J Gen Virol 89:676-686. https://doi.org/ 10.1099/vir.0.83320-0

60. Akhrymuk I, Lukash T, Frolov I, Frolova El. 2019. Novel mutations in nsP2 abolish chikungunya virus-induced transcriptional shutoff and make the virus less cytopathic without affecting its replication rates. J Virol 93: e02062-18. https://doi.org/10.1128/JVI.02062-18.

61. Fros JJ, Pijlman GP. 2016. Alphavirus infection: host cell shut-off and inhibition of antiviral responses. Viruses 8:166. https://doi.org/10.3390/ v8060166.

62. Nikonov A, Molder T, Sikut R, Kiiver K, Mannik A, Toots U, Lulla A, Lulla V, Utt A, Merits A, Ustav M. 2013. RIG-I and MDA-5 detection of viral RNA-dependent RNA polymerase activity restricts positive-strand RNA virus replication. PLoS Pathog 9:e1003610. https://doi.org/10.1371/ journal.ppat.1003610.

63. Australian Government, NHMRC, ARC. 2013. Australian code for the care and use of animals for scientific purposes. https://www.nhmrc.gov.au/ about-us/publications/australian-code-care-and-use-animals-scientific -purposes. Accessed 31 January 2020.

64. Kuhn RJ, Niesters HG, Hong Z, Strauss JH. 1991. Infectious RNA transcripts from Ross River virus cDNA clones and the construction and characterization of defined chimeras with Sindbis virus. Virology 182: 430-441. https://doi.org/10.1016/0042-6822(91)90584-x.

65. Dalgarno L, Rice CM, Strauss JH. 1983. Ross River virus 26 s RNA: complete nucleotide sequence and deduced sequence of the encoded structural proteins. Virology 129:170-187. https://doi.org/10.1016/0042 -6822(83)90404-x.

66. Lidbury BA, Mahalingam S. 2000. Specific ablation of antiviral gene expression in macrophages by antibody-dependent enhancement of Ross River virus infection. J Virol 74:8376-8381. https://doi.org/10.1128/ jvi.74.18.8376-8381.2000.

67. Lidbury BA, Simeonovic C, Maxwell GE, Marshall ID, Hapel AJ. 2000. Macrophage-induced muscle pathology results in morbidity and mortality for Ross River virus-infected mice. J Infect Dis 181:27-34. https:// doi.org/10.1086/315164.

68. Herrero LJ, Nelson M, Srikiatkhachorn A, Gu R, Anantapreecha S, Fingerle-Rowson G, Bucala R, Morand E, Santos LL, Mahalingam S. 2011. Critical role for macrophage migration inhibitory factor (MIF) in Ross River virus-induced arthritis and myositis. Proc Natl Acad Sci U S A 108:12048-12053. https://doi.org/10.1073/pnas.1101089108.

69. Morrison TE, Whitmore AC, Shabman RS, Lidbury BA, Mahalingam S, Heise MT. 2006. Characterization of Ross River virus tropism and virusinduced inflammation in a mouse model of viral arthritis and myositis. J Virol 80:737-749. https://doi.org/10.1128/JVI.80.2.737-749.2006.

70. Liu WJ, Wang XJ, Clark DC, Lobigs M, Hall RA, Khromykh AA. 2006. A single amino acid substitution in the West Nile virus nonstructural protein NS2A disables its ability to inhibit alpha/beta interferon induction and attenuates virus virulence in mice. J Virol 80:2396-2404. https:// doi.org/10.1128/JVI.80.5.2396-2404.2006. 